\title{
Wave boundary layer model in SWAN revisited
}

\author{
Jianting Du ${ }^{1,3,4}$, Rodolfo Bolaños ${ }^{2}$, Xiaoli Guo Larsén ${ }^{1}$, and Mark Kelly ${ }^{1}$ \\ ${ }^{1}$ Department of Wind Energy, Technical University of Denmark, Risø, Campus, Roskilde, Denmark \\ ${ }^{2}$ DHI, Agern Allé 5, Hørsholm, Denmark \\ ${ }^{3}$ First Institute of Oceanography, Ministry of Natural Resources of China, Qingdao, China \\ ${ }^{4}$ Laboratory for Regional Oceanography and Numerical Modeling, Qingdao National Laboratory \\ for Marine Science and Technology, Qingdao, China
}

Correspondence: Jianting Du (dujt@fio.org.cn)

Received: 25 July 2018 - Discussion started: 6 August 2018

Revised: 30 November 2018 - Accepted: 13 December 2018 - Published: 10 April 2019

\begin{abstract}
In this study, we extend the work presented in Du et al. (2017) to make the wave boundary layer model (WBLM) applicable for real cases by improving the windinput and white-capping dissipation source functions. Improvement via the new source terms includes three aspects. First, the WBLM wind-input source function is developed by considering the impact of wave-induced wind profile variation on the estimation of wave growth rate. Second, the white-capping dissipation source function is revised to be not explicitly dependent on wind speed for real wave simulations. Third, several improvements are made to the numerical WBLM algorithm, which increase the model's numerical stability and computational efficiency. The improved WBLM wind-input and white-capping dissipation source functions are calibrated through idealized fetch-limited and depth-limited studies, and validated in real wave simulations during two North Sea storms. The new WBLM source terms show better performance in the simulation of significant wave height and mean wave period than the original source terms.
\end{abstract}

\section{Introduction}

The accuracy of spectral ocean wave models depends on the forcing from wind, water level, currents, etc. It also depends on the source terms and numerical methods (Ardhuin, 2012). In deep water conditions, the source terms are reduced to the wind-input source function $\left(S_{\text {in }}\right)$, wave-breaking dissipation source function $\left(S_{\mathrm{ds}}\right)$, and nonlinear four-wave-interaction source function $\left(S_{\mathrm{nl}}\right)$. In a previous study (Du et al., 2017), a wave boundary layer model (WBLM) was implemented in the third-generation Simulating WAves Nearshore (SWAN) ocean wave model (Booij et al., 1999) to improve the windinput source function of Janssen (1991, hereafter JANS); this was done by considering the momentum and kinetic energy conservation at each level in the wave boundary layer. It was shown that the new $S_{\text {in }}$ improves wave simulations in idealized fetch-limited conditions. Because the evolution of wave spectra depends on the difference between source and sink terms, the change of $S_{\text {in }}$ has to be followed by the tuning of the parameters in $S_{\mathrm{ds}}$ (Cavaleri, 2009). Du et al. (2017) simply recalibrated the white-capping dissipation parameters of Komen et al. (1984, hereafter KOM) to be proportional to the WBLM $S_{\text {in }}$ (Babanin et al., 2010) and wind speed at $10 \mathrm{~m}\left(U_{10}\right)$ (Melville and Matusov, 2002). Such a method works in idealized fetch-limited conditions when the winds do not change over time. However, in real cases, wind speed and direction vary in time. Also, wave breaking is related to wave properties such as wave steepness, rather than explicitly dependent on wind speed (e.g., Komen et al., 1994). Moreover, in coastal areas, the bottom friction and depth-induced breaking dissipation become important and they influence the shape of wave spectra. Consequently, $S_{\text {in }}$ and $S_{\mathrm{ds}}$ are also modified by the shallow-water effect. Therefore, the description of the new $S_{\mathrm{in}}$ and $S_{\mathrm{ds}}$ in shallow water also needs to be investigated before they are used in real simulations.

Theoretical models of wave-breaking dissipation have been extensively reviewed by Komen et al. (1994), Young and Babanin (2006a), and Cavaleri et al. (2007), and can be classified into white-capping models (Hasselmann, 1974), saturation-based models (e.g., Phillips, 1985), probabilistic 
models (e.g., Longuet-Higgins, 1969; Yuan et al., 1986; Hua and Yuan, 1992), and turbulent models (Polnikov, 1993). Among them, white-capping and saturation-based models are widely used in ocean wave models such as WAM (Komen et al., 1994), Simulating WAves Nearshore (SWAN) (Booij et al., 1999), WAVEWATCH III (Tolman and Chalikov, 1996), and MIKE 21 SW (Sørensen et al., 2005). Whitecapping models consider the effect of downward-moving whitecaps doing work against the upward-moving waves. Parameterization of white-capping dissipation can be found in, e.g., Komen et al. (1984), Bidlot et al. (2007), and Bidlot (2012); the dissipation at all frequencies is taken to be proportional to the mean wave steepness defined by a mean wave number and the significant wave height. The saturationbased models assume saturation exists in the equilibrium range of the wave spectrum, and the dissipation rate is proportional to the saturation at any given frequency. Therefore, the dissipation at each frequency is proportional to the local wave steepness or local saturation. Latter studies, however, suggest a two-phase behavior of wave-breaking dissipation (Babanin and Young, 2005; Young and Babanin, 2006a): $S_{\mathrm{ds}}$ should be a function of the spectral peak plus a cumulative frequency-integrated term at higher frequencies due to dominant wave breaking. Considering the complexity of wave-breaking processes, recent studies tend to combine the two types of $S_{\mathrm{ds}}$ together. Alves and Banner (2003) and van der Westhuysen et al. (2007) used a saturation-based model multiplied by a KOM-shaped model to account for the longwave-shortwave and wave-turbulence interactions. Banner and Morison (2010) introduced a breaking probability function to the saturation-based model of Phillips (1985). Ardhuin et al. (2010), Babanin et al. (2010), and Zieger et al. (2015) added a cumulative term to a saturation-based model. Such combined $S_{\mathrm{ds}}$ values are proven to be robust in wave simulations, globally to coastal areas (Ardhuin et al., 2012; Ardhuin and Roland, 2012; Leckler et al., 2013).

However, as more physical processes are being taken into account, expressions of $S_{\mathrm{ds}}$ become more complex and need more tuning parameters; e.g., the $S_{\mathrm{ds}}$ of Ardhuin et al. (2010) needs up to 18 parameters, which makes it difficult to adjust when there is modification of other source terms. The present study aims at finding a proper dissipation source function that is suitable for the new WBLM $S_{\text {in. Therefore, instead }}$ of introducing more physics into $S_{\mathrm{ds}}$, numerical adjustment is applied to the KOM dissipation (Komen et al., 1984). The reason that we chose the KOM $S_{\mathrm{ds}}$ is that it has been shown to be successful when used with different wind-input source functions in SWAN (Snyder et al., 1981; Komen et al., 1984; Janssen, 1991; Larsén et al., 2017), and because the formulation is so flexible that its total magnitude and spectral distribution can be easily tuned with $C_{\mathrm{ds}}$ and $\Delta$ in Eq. (12). Du et al. (2017) has shown that numerical adjustment to the KOM $S_{\mathrm{ds}}$ can be used for the WBLM $S_{\text {in }}$, to reproduce the fetch-limited wave growth curve of Kahma and Calkoen (1992). Moreover, Ardhuin (2012) showed that $S_{\mathrm{ds}}$ of the
KOM type and saturation-based type (Phillips, 1985) can be adjusted to give very similar behavior. However, we found that using only the KOM $S_{\mathrm{ds}}$ within the WBLM produces a too-high energy level at frequencies higher than the spectral peak $\left(f>f_{\mathrm{p}}\right)$, and this problem can be solved by using a cumulative dissipation term according to Ardhuin et al. (2010).

In this paper, the improvement of WBLM $S_{\text {in }}$, the revised $S_{\mathrm{ds}}$, and the numerical algorithm changes to the model are presented in Sect. 2. Then, the new pair of $S_{\mathrm{in}}$ and $S_{\mathrm{ds}}$ is calibrated in idealized fetch-limited and depth-limited studies, and validated in real-case storm simulations in the North Sea. These numerical experiments are described in Sect. 3, and the results are presented in Sect. 4. Wave parameters such as significant wave height, mean period, peak wave period, and spectral shape are validated using point measurements of deep and shallow waters. $S_{\text {in }}$ and $S_{\mathrm{ds}}$ of KOM and JANS are also examined as a benchmark reference for these storms. As mentioned before, wave growth depends on the difference between source and sink terms as well as numerical discretization methods, especially in real cases. Therefore, it is difficult to distinguish whether an improvement of a specific wave parameter, such as significant wave height, is due to the improvement of $S_{\text {in }}$ or $S_{\mathrm{ds}}$. An evaluation of the WBLM $S_{\text {in }}$ was presented in Du et al. (2017) in an idealized fetch-limited wave growth study, where the wave growth rate and the drag coefficient calculated from $S_{\text {in }}$ are compared with measurements. However, this paper mainly focuses on the application of WBLM for real applications, so that the overall effect of the new WBLM $S_{\text {in }}$ and $S_{\mathrm{ds}}$ is emphasized.

\section{Methods}

\subsection{The wind-input source function}

According to $\mathrm{Du}$ et al. (2017), the growth rate $\left(\beta_{\mathrm{g}}\right)$ of the WBLM wind-input source function $\left(S_{\text {in }}=\beta_{\mathrm{g}}(\sigma, \theta) N(\sigma, \theta)\right)$ is expressed as

$\beta_{\mathrm{g}}(\sigma, \theta)=C_{\beta} \sigma \frac{\tau_{\mathrm{t}}(z)}{\rho_{\mathrm{w}} c^{2}} \cos ^{2}\left(\theta-\theta_{\mathrm{w}}\right)$,

where $N(\sigma, \theta)$ is the action density spectrum, $\theta$ and $\theta_{\mathrm{w}}$ are the wave and wind directions, $C_{\beta}$ is the Miles parameter (Miles, 1957), $\rho_{\mathrm{w}}$ is the water density, and $c$ is the phase velocity of waves. $\tau_{\mathrm{t}}(z)$ is the local turbulent stress, which is equal to the total stress, $\tau_{\mathrm{tot}}$, minus the wave-induced stress, $\tau_{\mathrm{w}}(z)$. The Miles parameter $C_{\beta}$ is described as a function of the non-dimensional critical height, $\lambda$ :

$C_{\beta}=\frac{J}{\kappa^{2}} \lambda \ln ^{4} \lambda, \lambda \leq 1$,

where $\kappa=0.41$ is the von Kármán constant, and $J=1.6$ is a constant. In Du et al. (2017), the expression of the nondimensional critical height $\lambda$ for Miles' parameter (Eq. 2) 
is derived by the assumption of a logarithmic wind profile following Janssen (1991), and it is expressed as

$\lambda=\frac{g z_{0}}{c^{2}} \exp \left[\frac{\kappa}{\left(u_{*} / c+\alpha\right) \cdot \cos \left(\theta-\theta_{\mathrm{w}}\right)}\right]$,

where $g$ is the gravity acceleration, $\alpha=0.008$ is a wave age tuning parameter according to Bidlot (2012), $z_{0}$ is the roughness length. However, it is found that using Eq. (3) causes numerical instability in some cases. This is because, within the WBL, the wind profile is not logarithmic under the impact of waves (Du et al., 2017). Using a logarithmic wind profile (Eq. 3) not only slows down the computation but could also fail in converging in some cases. Therefore, when applying WBLM $S_{\text {in }}$, the expression of $\lambda$ also needs to be changed to adjust to the new wind profile. Here, we follow Miles (1957)'s procedure to drive an approximate expression for $\lambda$. In Miles (1957), the non-dimensional critical height is defined as

$\lambda=k z_{\mathfrak{c}}$,

where $k$ is the wave number, $z_{\mathrm{c}}$ is the critical height where the wave phase velocity $(c)$ equals the wind speed component in the phase velocity direction $u\left(z_{\mathrm{c}}\right) \cdot \cos \left(\theta-\theta_{\mathrm{w}}\right)$,

$c=u\left(z_{\mathrm{c}}\right) \cdot \cos \left(\theta-\theta_{\mathrm{w}}\right)$

where $\theta-\theta_{\mathrm{w}}$ is the angular separation between wind and wave directions. We assume that, in the vicinity of the critical height $\left(z_{\mathrm{c}}\right)$, the wind profile can be approximately described as locally logarithmic:

$$
\frac{\mathrm{d} u}{\mathrm{~d} z}=\frac{u_{*}^{1}}{\kappa z},
$$

where $u_{*}^{1}=\sqrt{\tau_{\mathrm{t}} / \rho_{\mathrm{a}}}$ is the local friction velocity. In the vicinity of the critical height, wind speed at any other heights $z$ can be expressed as

$u(z)=\frac{u_{*}^{1}}{\kappa} \ln (z)+z_{0}^{1}$,

where $z_{0}^{1}$ is a local effective roughness. Introducing Eqs. (7)(5), we have wind speed at the critical height:

$u\left(z_{\mathrm{c}}\right)=\frac{c}{\cos \left(\theta-\theta_{\mathrm{w}}\right)}=\frac{u_{*}^{1}}{\kappa} \ln \left(z_{\mathrm{c}}\right)+z_{0}^{1}$.

The critical height is calculated by combining Eqs. (7) and (8):

$z_{\mathrm{c}}=z \cdot \exp \left[\frac{\kappa}{\left(u_{*}^{1} / c\right) \cdot \cos \left(\theta-\theta_{\mathrm{w}}\right)}-\frac{\kappa u(z)}{u_{*}^{1}}\right]$.

Considering the shallow-water dispersion relation, $k=$ $\left(g / c^{2}\right) \tanh (k h)$, with $h$ the water depth, the combination of
Eqs. (4) and (9) results in the non-dimensional critical height for any direction:

$$
\begin{aligned}
\lambda & =k z_{\mathrm{c}}=\frac{g z}{c^{2}} \tanh (k h) \cdot \exp \\
& {\left[\frac{\kappa}{\left(u_{*}^{1} / c\right) \cdot \cos \left(\theta-\theta_{\mathrm{w}}\right)}-\frac{\kappa u(z)}{u_{*}^{1}}\right] . }
\end{aligned}
$$

It is found that Eq. (10) tends to underestimate wave growth at low frequencies. We used the same method as that used in WAM (Bidlot, 2012) and added a wave age tuning parameter $(\alpha=0.011)$ to shift the wave growth towards lower frequencies:

$$
\begin{aligned}
\lambda & =\frac{g z}{c^{2}} \tanh (k h) \cdot \exp \\
& {\left[\frac{\kappa}{\left(u_{*}^{1} / c+\alpha\right) \cdot \cos \left(\theta-\theta_{\mathrm{w}}\right)}-\frac{\kappa u(z)}{u_{*}^{1}}\right] . }
\end{aligned}
$$

\subsection{White-capping dissipation source function}

The white-capping dissipation expression of KOM (Komen et al., 1984; Janssen, 1991; Bidlot et al., 2007) in SWAN is written as

$$
\begin{aligned}
S_{\mathrm{ds}}(\sigma, \theta) & =-C_{\mathrm{ds}}\langle\sigma\rangle\left(\langle k\rangle^{2} m_{0}\right)^{2} \\
& {\left[(1-\Delta) \frac{k}{\langle k\rangle}+\Delta\left(\frac{k}{\langle k\rangle}\right)^{2}\right] \phi(\sigma, \theta), }
\end{aligned}
$$

where $\phi(\sigma, \theta)=\sigma N(\sigma, \theta)$ is the frequency spectra. Since the WBLM wind-input and dissipation source functions are designed mainly for the wind sea, it is necessary to reduce the swell impact to the white-capping dissipation. In this study, the mean radian frequency $\langle\sigma\rangle$ and mean wave number $\langle k\rangle$ are modified according to Bidlot et al. (2007) to put more emphasis on the high frequencies:

$$
\left\{\begin{array}{l}
\langle\sigma\rangle=\iint \sigma \phi(\sigma, \theta) \mathrm{d} \theta \mathrm{d} \sigma / m_{0} \\
\langle k\rangle=\left[\iint k^{1 / 2} \phi(\sigma, \theta) \mathrm{d} \theta \mathrm{d} \sigma / m_{0}\right]^{2},
\end{array}\right.
$$

where $m_{0}=\iint \phi(\sigma, \theta) \mathrm{d} \theta \mathrm{d} \sigma$ is the variance of the sea surface elevation. The choice of the two dissipation parameters, $C_{\mathrm{ds}}$ and $\Delta$, is different for different wind-input source functions. For example, for KOM $S_{\mathrm{in}}, C_{\mathrm{ds}}=2.5876$ and $\Delta=1$; for JANS $S_{\mathrm{in}}, C_{\mathrm{ds}}=4.5$, and $\Delta=0.5$; for WBLM $S_{\text {in }}$ in Du et al. (2017), $\Delta=0.1$, and $C_{\mathrm{ds}}$ in $S_{\mathrm{ds}}$ is related to $S_{\text {in }}$ to make sure

$$
\int S_{\mathrm{ds}}(\sigma) \mathrm{d} \sigma=R_{\mathrm{ds}} \int S_{\text {in }}(\sigma) \mathrm{d} \sigma,
$$


where

$$
\begin{aligned}
R_{\mathrm{ds}}= & 1-0.15\left(\frac{10}{U_{10}}\right)^{0.5} \cdot \max \\
& {\left[1.0,1.53\left(\frac{5.2 \times 10^{-7}}{\widetilde{E}}\right)^{0.25}\right], }
\end{aligned}
$$

where $U_{10}$ is wind speed at $10 \mathrm{~m}$, and $\widetilde{E}=m_{0} g^{2} / U_{10}^{4}$ is a non-dimensional energy. As discussed in the introduction, a dissipation parameter that is strongly dependent on wind speed as in Eq. (15) only works in idealized fetch-limited cases but will in principle not work in real cases because wave breaking depends on wave state rather than wind. Here, we explore the use of some wave parameters to replace $U_{10}$ and $S_{\text {in }}$ in Eqs. (14) and (15) to get rid of the direct dependence on wind speed. We derive the relationship between $U_{10}, m_{0}$, peak frequency $\left(f_{\mathrm{p}}\right)$, and fetch $(x)$ from the three non-dimensional parameters, namely non-dimensional energy $(\widetilde{E})$, non-dimensional peak frequency $\left(\widetilde{F}_{\mathrm{p}}=f_{\mathrm{p}} U_{10} / g\right)$, and non-dimensional fetch $\left(\tilde{x}=x g / U_{10}^{2}\right)$. The fetch dependence of $\widetilde{E}$ and $\widetilde{F}_{\mathrm{p}}$ can be written as

$$
\left\{\begin{array}{l}
\widetilde{E}=A \widetilde{x}^{B} \\
\widetilde{F}_{\mathrm{p}}=C \widetilde{x}^{D},
\end{array}\right.
$$

where, in Kahma and Calkoen (1992) (composite condition), $A=5.2 \times 10^{-7}, B=0.9, C=2.1804, D=-0.27$. According to Eq. (16), $U_{10}, \widetilde{E}$, and $\widetilde{x}$ can be expressed as functions of $m_{0}, f_{\mathrm{p}}$, and $g$ :

$$
\left\{\begin{array}{l}
U^{\prime}=\left[\frac{C^{B}}{A^{D}} \frac{m_{0}^{D}}{f_{\mathrm{p}}^{B}} g^{2 D+B}\right]^{\frac{1}{4 D+B}} \\
E^{\prime}=m_{0} g^{2} / U^{\prime 4} \\
x^{\prime}=\left(E^{\prime} / A\right)^{1 / B}
\end{array}\right.
$$

where $U_{10}, \widetilde{E}$, and $\widetilde{x}$ are replaced by $U^{\prime}, E^{\prime}$, and $x^{\prime}$ since they are parameterized variables. The dissipation coefficient $C_{\mathrm{ds}}$ in Eq. (12) can be obtained by fitting the $C_{\mathrm{ds}}$ calculated from Eqs. (14) and (15) with $U^{\prime}$ and $x^{\prime}$ from Eq. (17):

$$
C_{\mathrm{ds}}=F\left(x^{\prime}, U^{\prime}\right)
$$

The form and parameters in Eq. (18) will be obtained in the fetch-limited study in Sect. 4.1. To increase the robustness of the wave modeling in the case of unusual-shaped spectra, the peak frequency $f_{\mathrm{p}}$ in Eq. (17) is replaced by $0.866\langle f\rangle$ according to Komen et al. (1994) who uses $k_{\mathrm{p}}=0.75\langle k\rangle$, where $\langle f\rangle=\langle\sigma\rangle / 2 \pi$ is the mean frequency. The use of $\langle f\rangle$ may cause uncertainty in estimating $f_{\mathrm{p}}$, especially in, e.g., bimodal wave cases. Considering the model performs quite well during the two storm simulations in Sect. 4.3, during which bimodal waves probably exist, we assume that this uncertainty is relatively small.
To reduce the energy level at high frequencies, a cumulative term is added to the dissipation source functions. The cumulative dissipation term $\left(S_{\mathrm{ds}}^{\mathrm{c}}\right)$ follows Ardhuin et al. (2010), but the directional dependence of dissipation rate is not considered:

$$
\begin{aligned}
S_{\mathrm{ds}}^{\mathrm{c}}(f, \theta) & =-1.44 \cdot C_{\mathrm{cu}} \phi(f, \theta) \int_{0}^{r_{\mathrm{cu}} f} \max \\
& {\left[\left(\sqrt{B\left(f^{\prime}\right)}-\sqrt{B_{\mathrm{r}}}\right), 0\right]^{2}\left|c-c^{\prime}\right|^{\prime} \mathrm{d} f^{\prime}, }
\end{aligned}
$$

where $C_{\mathrm{cu}}=1.0$ is a dissipation parameter, $B_{\mathrm{r}}=0.0012$ is a saturation threshold, $r_{\mathrm{cu}}=0.5$ is the ratio of the maximum frequency where dissipation of long waves influences short waves, $C_{\mathrm{g}}$ is the group velocity, and $B(f)$ is the local saturation (van der Westhuysen et al., 2007):

$B(f)=\int_{0}^{2 \pi} k^{3} \cos ^{2}\left(f, \theta^{\prime}\right) \phi\left(f, \theta^{\prime}\right) \frac{C_{\mathrm{g}}}{2 \pi} \mathrm{d} \theta^{\prime}$.

\subsection{Improvement of the numerical algorithm}

Considering the expensive cost of WBLM code in Du et al. (2017), improvement of the numerical algorithm of the WBLM (Du et al., 2017) was done in the following aspects.

- The unnecessary calculations in the high frequencies were reduced. The WBLM uses $10 \mathrm{~Hz}$ as the maximum frequency, which is only being used for very young waves. Usually, the WBLM does not have to solve such high frequencies when the energy is so small that their contribution to the total wave-induced stress is negligible. Therefore, in the new code, the WBLM only solves the active frequency range which is dynamically changing with the wave spectrum. Although the maximum frequency is dynamically changing, all the active frequencies are solved, so there is no influence on the result. Such an adjustment reduces approximately half of the computation time in the idealized fetch-limited study in Sect. 3.1.

- The standard calculation in SWAN, a sweeping technique is used for the directional propagation of the waves, needs to be swept four times for each time step. Such a sweep is not necessary for the calculation of WBLM because the WBLM has to integrate over all directions of the spectra. Therefore, WBLM only calculates once per time step.

With the above mentioned refinement, the WBLM is now about 5 times faster than the previous version in $\mathrm{Du}$ et al. (2017). It is still slower than KOM and JANS, but it is fast enough for real applications. The averaged calculation time during an idealized fetch-limited study is listed in Table 1, including KOM, JANS, the previous WBLM of Du et al. 
Table 1. The calculation time of KOM, JANS, the previous WBLM of Du et al. (2017) (WBM Old), and the new WBLM during the idealized fetch-limited study.

\begin{tabular}{lrrrr}
\hline Scheme & KOM & JANS & WBLM Old & New WBLM \\
\hline Time (min) & 184 & 151 & 975 & 217 \\
\hline
\end{tabular}

(2017) (WBM Old), and the new WBLM in this paper. All the setups are the same as those in Sect. 3.1, except JANS uses frequency number ranges from 38 to 54 for different wind speed conditions, while the other schemes use 73 frequencies.

\section{Experiments}

\subsection{Idealized fetch-limited study}

The revised dissipation parameter (Eq. 18) in $S_{\mathrm{ds}}$ together with the new non-dimensional critical height as in WBLM $S_{\text {in }}$ were first calibrated in the idealized fetch-limited wave growth experiments with the same model setup as in Du et al. (2017). Here, we briefly describe the model setup. We use the one-dimensional SWAN. The fetch is between 0 and $3000 \mathrm{~km}$, with the spatial resolution changing gradually from 0.1 to $10 \mathrm{~km}$. The wave spectrum ranges from 0.01 to $10.51 \mathrm{~Hz}$, and the frequency discretization was logarithmic with a frequency exponent of 1.1, which results in 73 frequencies. We use 36 directional bins with a constant spacing of $10^{\circ}$. SWAN initializes from zero spectrum and runs for $72 \mathrm{~h}$ with a time step of $1 \mathrm{~min} . U_{10}$ ranges from 5 to $40 \mathrm{~ms}^{-1}$ and keeps constant during the $72 \mathrm{~h}$ simulation.

The calibration process is carried out in three steps. In Step 1, we run the model using the white-capping dissipation parameter as in Du et al. (2017) (Eqs. 14 and 15) in the idealized fetch-limited study. Since we added a cumulative dissipation source term, the parameters in Eq. (15) have to be changed into Eq. (21) so as to best fit to the Kahma and Calkoen (1992) fetch-limited wave growth curves:

$$
\begin{aligned}
R_{\mathrm{ds}} & =1-0.18\left(\frac{10}{U_{10}}\right)^{0.3} \cdot \max \\
& {\left[1.0,1.53\left(\frac{5.2 \times 10^{-7}}{\widetilde{E}}\right)^{0.25}\right] . }
\end{aligned}
$$

In Step 2, the real form and parameters in Eq. (18) will be obtained by analyzing and fitting the $C_{\mathrm{ds}}$ with $x^{\prime}$ and $U^{\prime}$, which are calculated in Step 1. Finally, the best fit in Step 2 may not be the best choice for the wave model. Therefore, we selected several representative fitting parameters out of dozens of groups through idealized fetch-limited study as the final choice.

\subsection{Idealized depth-limited study}

In addition to the idealized fetch-limited study, the revised WBLM source terms are also tested in depth-limited wave growth experiments to check if the new source terms perform well with the interaction of the other source terms in the wave model, including the bottom friction and depthinduced wave-breaking dissipation source functions. Following SWAN (2014), we use JONSWAP (Hasselmann et al., 1973) bottom friction with a bottom friction coefficient, $C_{\mathrm{b}}=0.038 \mathrm{~m}^{2} \mathrm{~s}^{-3}$, and Battjes and Janssen (1978) depthinduced wave-breaking source function with a breaker parameter, $\gamma=0.8$.

In the depth-limited wave growth experiments, we take the measurements of Young and Babanin (2006b) as reference for validation, because they not only provided detailed wind, wave, and water depth information but also provided wave spectrum measurement from capacitance wave probes up to $10 \mathrm{~Hz}$ (Young et al., 2005). Zijlema et al. (2012) conducted similar depth-limited wave growth experiments for the calibration of the bottom friction parameter in SWAN, but they did not compare the wave spectrum. Zijlema et al. (2012) selected 10 representative cases from the data presented in Young and Babanin (2006b). We add three more cases because the wave spectra in these three cases are also presented in Young and Babanin (2006b). This ends up with 13 cases in all, which are numbers $1,11,17,23,28,30,32,58,61$, 63, 82, 83, and 87 in Table 1 of Young and Babanin (2006b). Among them, numbers $1,11,28,32$, and 87 have wave spectrum records for model validation. In all 13 cases, the water depth ranges from 0.89 to $1.1 \mathrm{~m}$, and the wind speed ranges from 5.7 to $15 \mathrm{~ms}^{-1}$. The fetch is set to $20 \mathrm{~km}$ with a spatial resolution of $0.1 \mathrm{~km}$ to ensure the fetch is long enough, and the wave growth is limited by the water depth. The frequency and directional discretization are same as those in the fetchlimited study. SWAN initializes from zero spectrum and runs for $24 \mathrm{~h}$ (we found $24 \mathrm{~h}$ is long enough for the wave development in the shallow-water conditions in this study), with a time step of $1 \mathrm{~min}$. Two pairs of $S_{\mathrm{in}}$ and $S_{\mathrm{ds}}$ are tested, namely KOM (Snyder et al., 1981; Komen et al., 1984) and the revised WBLM in this study.

\subsection{Real case study in the North Sea}

The new WBLM $S_{\text {in }}$ and $S_{\mathrm{ds}}$ are validated during two winter storms in the North Sea. Wind and wave measurements are obtained during the "Reducing the uncertainty of near-shore wind estimations using wind lidars and mesoscale models" (RUNE) project (Floors et al., 2016b). Simultaneous wind and wave measurements from lidar and buoys are available from November 2015 to January 2016. The experiment was conducted on the west coast of Jutland, Denmark, with an average water depth of $16.5 \mathrm{~m}$. Details about the wind and wave measurements can be found in Floors et al. (2016b, a, c), Bolaños (2016), and Bolaños and Rørbæk (2016). Be- 


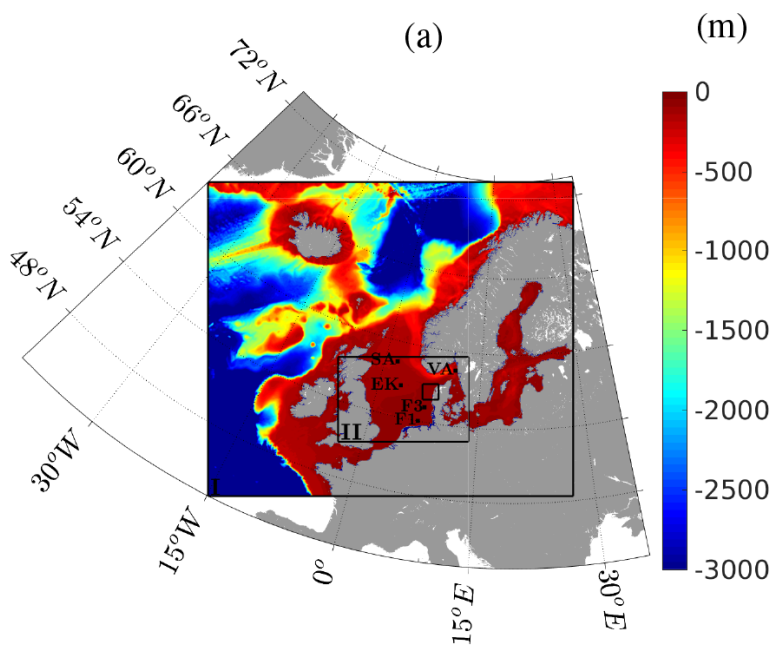

(b)

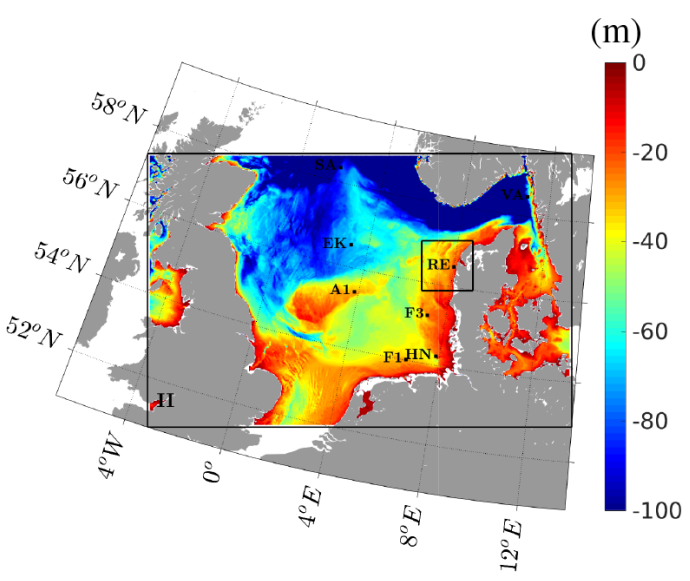

(c)

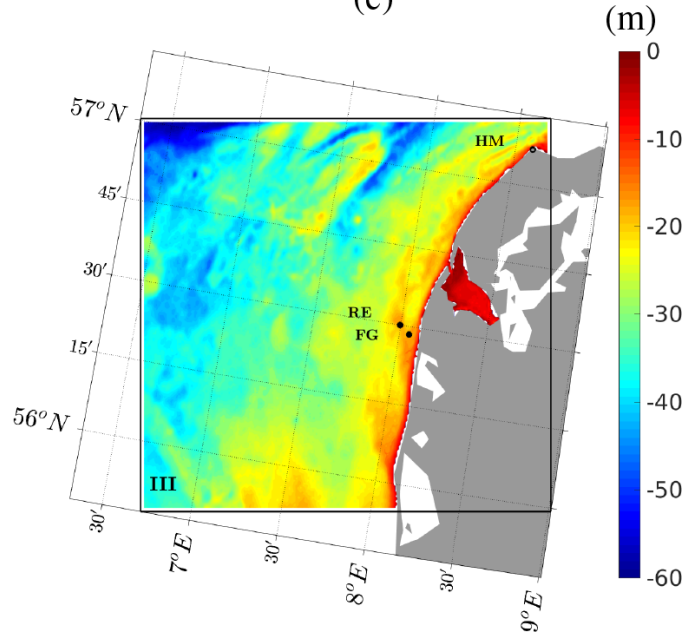

Figure 1. SWAN domain for "Reducing the uncertainty of near-shore wind estimations using wind lidars and mesoscale models" (RUNE) storm simulation, with domains I at $9 \mathrm{~km}$ resolution, II at $3 \mathrm{~km}$ resolution, and III at $600 \mathrm{~m}$ resolution. Panels (a, b, c) show the bathymetry at domain I, II, and III. Bathymetry data are interpolated from EMODnet digital terrain model (DTM) $1 / 8$ arcmin data. The five measurement sites, RUNE (RE), Fjaltring (FG), Hanstholm (HM), A121 (A1), Väderöarna (VA), Heligoland north (HN), Fino-1 (F1), Fino-3 (F3), Sleipner-A (SA), and Ekofisk (EK), are shown as black dots.

sides the standard wave parameters such as significant wave heights, peak wave period, and mean wave periods, the twodimensional wave spectra $E(f, \theta)$ are also available, which allows us to validate more detailed aspects of the source functions. During the RUNE period, two storms passed the measurement site on 28 November 2015 and 12 August 2015. Wave simulations were done during this period with the three pairs of source terms (KOM, JANS, and WBLM). Besides the measurement from the RUNE project, point wave measurements at Fjaltring, Hanstholm, A121, Väderöarna, and Heligoland north from NOOS (https://noos.bsh.de/, last access: 15 June 2017) FINO-1 and FINO-3 from FINO (http: //fino.bsh.de, last access: 3 April 2018) and Sleipner-A and Ekofisk from eKlima (http://sharki.oslo.dnmi.no, last access:
17 November 2016) during the simulation period are also used for model validation. The locations of these measurement sites are shown in Fig. 1a, b, and c.

SWAN is forced by the National Centers for Environmental Prediction (NCEP) Climate Forecast System version 2 (CFSv2) $10 \mathrm{~m}$ wind (Saha et al., 2011). The quality of CFSv2 $10 \mathrm{~m}$ wind speed and direction is evaluated with measurements in Fig. 6a-b, and it has been shown to be good quality for wave simulations in the North Sea in many previous studies (Bolaños et al., 2014). Therefore, the hourly CFSv2 data may be considered reasonable wind forcing, though it may not be accurate in the presence of highly fluctuating wind on scales smaller than $1 \mathrm{~h}$, e.g., Larsén et al. (2017). SWAN uses three nested domains, with a resolution downscaling from 9 

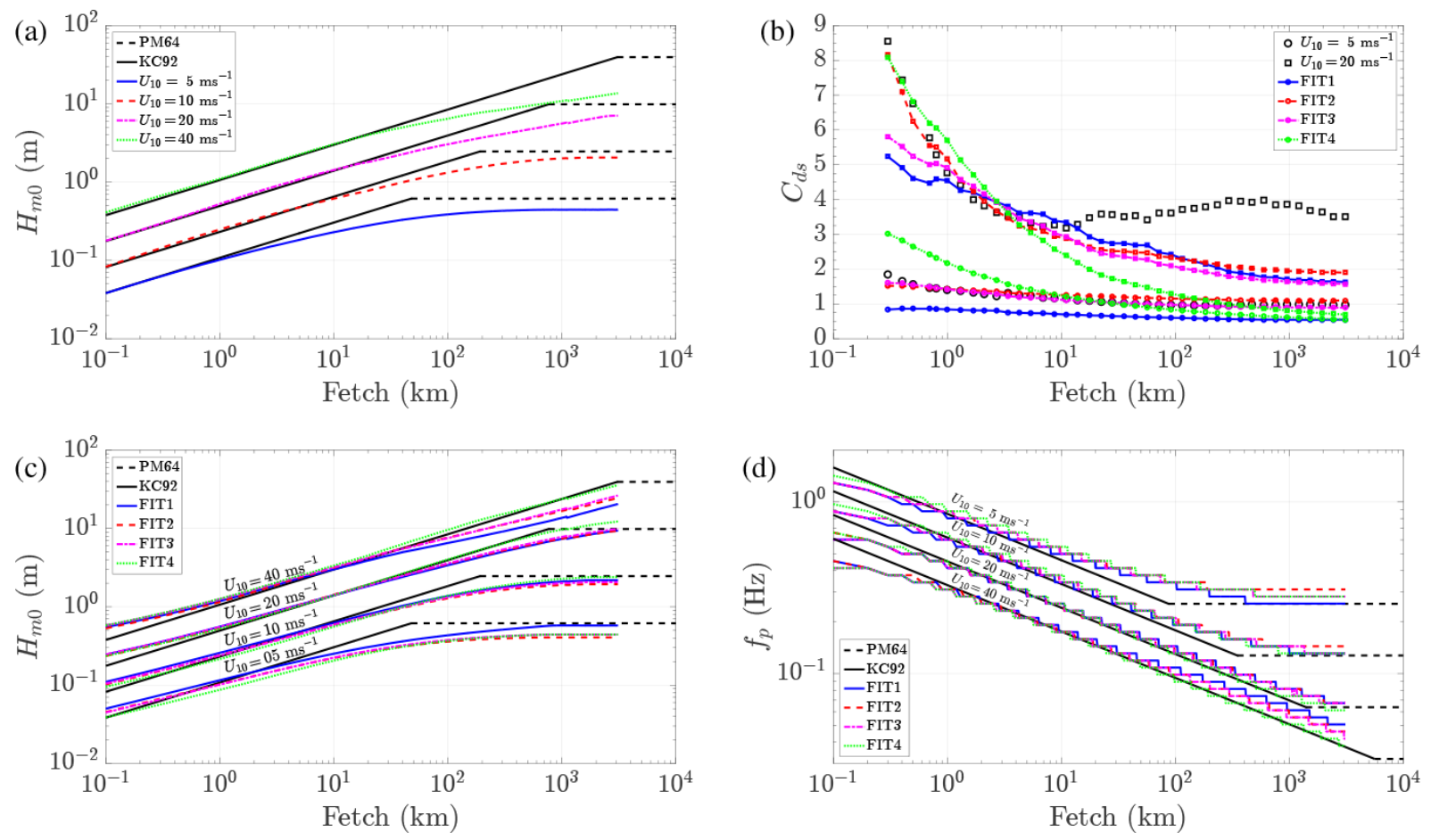

Figure 2. $H_{m 0}$ as a function of fetch after $72 \mathrm{~h}$ of simulation in different wind speed conditions using Eq. (21) as the white-capping dissipation parameter (a). $C_{\mathrm{ds}}$ as a function of fetch after $72 \mathrm{~h}$ of simulation in different wind speed conditions using Eq. (21), and fitted $C_{\mathrm{ds}}$ using FIT1 to FIT4 (b). $H_{m 0}$ and $f_{\mathrm{p}}$ as a function of fetch using white-capping dissipation parameters from FIT1 to FIT4 (c, d).

to $3 \mathrm{~km}$ and $600 \mathrm{~m}$ (Fig. 1a). Open boundaries for SWAN are set to 0 . The shortest fetch of the observation points is larger than $1000 \mathrm{~km}$ according to the wind direction during the storm. According to the fetch-limited study in Sect. 4.1, the fetch is long enough for the waves to develop. The bottom friction and depth-induced wave-breaking source functions for the real case study are same as the depth-limited wave growth studies. Bathymetry data are obtained from the EMODnet digital terrain model (DTM) with a spatial resolution of $1 / 8$ arcmin. Note that most of the observations are located in the coastal areas in the North Sea, except SleipnerA, A121, and Ekofisk (Fig. 1b, c). The water depth of most sites is less than $30 \mathrm{~m}$, except Sleipner-A and Ekofisk, which are relatively deeper, with water depth around 80 and $60 \mathrm{~m}$, respectively. SWAN initializes from zero spectrum, and the first $24 \mathrm{~h}$ output are not included in our analysis. The first storm peak is about $72 \mathrm{~h}$ after the model initializes to make sure the duration of the simulation is long enough. The frequency discretization was logarithmic with a frequency exponent of 1.1, and the lowest frequency was set to $0.03 \mathrm{~Hz}$. For the KOM and WBLM source terms, a cut-off frequency of $10.05 \mathrm{~Hz}$ is used, giving a total of 61 frequencies; for JANS source terms, the cut-off frequency is set to $0.57 \mathrm{~Hz}$ to make sure the simulation is stable, giving a total of 31 frequencies. We used 36 directional bins and a 5 min time step. A summary of the constants and model setups used for all the experiments in Sect. 3 is given in Tables 2 and 3, respectively.

\section{Results}

\subsection{Idealized fetch-limited study}

The significant wave height $\left(H_{m 0}\right)$ calculated from Step 1 of the idealized fetch-limited study using Eqs. (14) and (21) is shown in Fig. 2a. The Kahma and Calkoen (1992) wave growth curves are also shown as solid black lines for reference. Note that Kahma and Calkoen (1992) curves come from data with limited wind speeds $\left(U_{10} \leq 25 \mathrm{~ms}^{-1}\right)$ and fetches $(x \leq 300 \mathrm{~km})$, and we linearly extend them to broader ranges. The $H_{m 0}$ calculated from Step 1 (solid colored lines in Fig. 2a) agrees with Kahma and Calkoen (1992) wave growth curves for fetches $x \leq 10 \mathrm{~km}$. But it tends to underestimate $H_{m 0}$ for fetches $x>10 \mathrm{~km}$. Therefore, in Step 2, we only fit the $C_{\mathrm{ds}}$ in the first $10 \mathrm{~km}$ and extend its application for longer fetches. The $C_{\mathrm{ds}}$ calculated from Step 1 for wind speed $U_{10}=5 \mathrm{~ms}^{-1}$ and $U_{10}=20 \mathrm{~ms}^{-1}$ is shown in Fig. $2 \mathrm{~b}$ as black circles and black rectangles. Here, we try to speculate the form of Eq. (18) based on the distribution of $C_{\mathrm{ds}}$ from Step 1 in Fig. 2b. First, $C_{\mathrm{ds}}$ has a clear dependence on $U_{10}$. We found that in $10 \mathrm{~ms}^{-1}$ wind speed conditions, the simulated $H_{m 0}$ follows the Kahma and Calkoen (1992) curves quite well in all fetches, while in the other wind speed conditions, the model underestimates $H_{m 0}$ when $U_{10}<10 \mathrm{~ms}^{-1}$ or overestimates $H_{m 0}$ when $U_{10}>10 \mathrm{~ms}^{-1}$. Therefore, we take $10 \mathrm{~ms}^{-1}$ as reference, and there should be a $\left(\frac{U^{\prime}}{10}\right)$ term 
Table 2. Constants used for all the experiments in Sect. 3. $C_{\mathrm{ds}}$ and $\Delta$ are white-capping dissipation parameters in Eq. (12); $F\left(x^{\prime}, U^{\prime}\right)$ is the new dissipation parameter for WBLM in Eq. (18); $C_{\mathrm{cu}}, B_{\mathrm{r}}$, and $r_{\mathrm{cu}}$ are cumulative dissipation parameter for WBLM in Eq. (19); $C_{\mathrm{b}}$ and $\gamma$ are JONSWAP (Hasselmann et al., 1973) bottom friction and Battjes and Janssen (1978) depth-induced wave-breaking parameters.

\begin{tabular}{lrrrrrrr}
\hline & $C_{\mathrm{ds}}$ & $\Delta$ & $C_{\mathrm{cu}}$ & $B_{\mathrm{r}}$ & $r_{\mathrm{cu}}$ & $C_{\mathrm{b}}\left(\mathrm{m}^{2} \mathrm{~s}^{-3}\right)$ & $\gamma$ \\
\hline KOM & 2.5876 & 1.0 & - & - & - & 0.038 & 0.8 \\
JANS & 4.5 & 0.5 & - & - & - & 0.038 & 0.8 \\
WBLM & $F\left(x^{\prime}, U^{\prime}\right)$ & 0.1 & 1.0 & 0.0012 & 0.5 & 0.038 & 0.8 \\
\hline
\end{tabular}

Table 3. A summary of model setups for all the experiments in Sect. 3. $\mathrm{d} x$ is the spatial resolution and $\mathrm{d} t$ is the time step of SWAN in seconds.

\begin{tabular}{lrrrrrrr}
\hline Experiments & Simulation time & $U_{10}\left(\mathrm{~ms}^{-1}\right)$ & Bathymetry & $\mathrm{d} x(\mathrm{~km})$ & $\mathrm{d} t(\mathrm{~s})$ & Frequency $(\mathrm{Hz})$ & Direction bins \\
\hline Fetch-limited & $72 \mathrm{~h}$ & $5.0-40$ & $5000 \mathrm{~m}$ & $0.1-10$ & 60 & $0.001-10.51$ & 36 \\
Depth-limited & $24 \mathrm{~h}$ & $5.7-15$ & $0.89-1.1 \mathrm{~m}$ & 0.1 & 60 & $0.001-10.51$ & 36 \\
\hline \multirow{2}{*}{ RUNE storms } & $\begin{array}{r}28 \text { November 2015 to } \\
\text { 12 August 2015 }\end{array}$ & CFSv2 & $\begin{array}{r}\text { EMODnet } \\
\text { DTM }\end{array}$ & $9-3-0.6$ & 300 & $0.003-10.05$ & $(0.57$ for JANS $)$ \\
\hline
\end{tabular}

in the $C_{\mathrm{ds}}$ equation. Second, $C_{\mathrm{ds}}$ depends on the fetch; considering the fetch dependence is logarithmic (the horizontal coordinate of Fig. 2b is logarithmic), there should be a $\ln (x)$ term in the $C_{\mathrm{ds}}$ equation. Considering that a log-transformed quantity must be unitless, we use the non-dimensional fetch $\ln \left(x^{\prime}\right)$ instead of $\ln (x)$. Therefore, we assume $C_{\mathrm{ds}}$ in Eq. (18) has the following form:

$C_{\mathrm{ds}}=\left[C 1 \cdot \ln ^{C 2}\left(x^{\prime}\right)+C 3\right] \cdot\left(\frac{U^{\prime}}{10}\right)^{C 4}$,

where $C 1, C 2, C 3$, and $C 4$ are parameters to be determined by fitting the $C_{\mathrm{ds}}$ calculated from Step 1 . Directly using the four parameters may be easier to fit, but it requires more effort to use or change it in real applications. Therefore, instead of finding a random combination of the four parameters that gives the least square error, we prefer to reduce the number of fitting parameters based on our understanding of the role of the two terms, namely $\ln \left(x^{\prime}\right)$ and $\left(\frac{U^{\prime}}{10}\right)$ in Eq. (22). We use fixed value for the power on $\ln \left(x^{\prime}\right)$ and $\left(\frac{U^{\prime}}{10}\right)$. By testing $1 \leq C 2 \leq 4$ with a resolution of 1 , and $0 \leq C 4 \leq 1$ with a resolution of 0.1 , we choose $C 2=2$ and $4, C 4=0.5$ and 1 as representative values. With the values of $C 2$ and $C 4$ provided, we fit $C 1$ and $C 3$ with the data from Step 1 and end up with the first three groups of fitting parameters listed in Table 4 (FIT1 to FIT3). FIT4 in Table 4 is an improvement for FIT3 which will be described latter. The fitted $C_{\mathrm{ds}}$ using FIT1 to FIT4 at different wind speed conditions is shown in Fig. $2 \mathrm{~b}$ as colored lines with circles and rectangles representing wind speed.

The four groups of parameters (FIT1 to FIT4 in Table 4) are applied in SWAN in the fetch-limited study, and the results are shown in Fig. 2c, d. The effect of the $\left(\frac{U^{\prime}}{10}\right)^{C 4}$
Table 4. Four groups of fitting parameters (FIT1, FIT2, FIT3, and FIT4) for Eq. (22).

\begin{tabular}{lrrrr}
\hline & $C 1$ & $C 2$ & $C 3$ & $C 4$ \\
\hline FIT1 & 30.74 & -4 & 1.169 & 1.0 \\
FIT2 & 83.61 & -4 & 1.605 & 0.5 \\
FIT3 & 13.08 & -2 & 1.241 & 0.5 \\
FIT4 & 23.02 & -1.41255 & 0.0 & 0.0 \\
\hline
\end{tabular}

term in Eq. (22) can be seen from the comparison between FIT1 and FIT2. The fitted $C_{\mathrm{ds}}$, simulated $H_{m 0}$, and $f_{\mathrm{p}}$ of FIT1 and FIT2 are shown in Fig. 2b, c, d as blue solid and red solid lines with circles and rectangles representing wind speed. Although significant difference of $C_{\mathrm{ds}}$ between $C 4=1.0$ (FIT1) and $C 4=0.5$ (FIT2) is seen in Fig. 2b, the resulting $H_{m 0}$ and $f_{\mathrm{p}}$ show a relatively small difference. In low wind speed conditions $\left(U_{10}=5\right.$ and $\left.10 \mathrm{~ms}^{-1}\right), C 4=1.0$ (blue solid lines in Fig. 2c, d) results in larger $H_{m 0}$ (smaller $f_{\mathrm{p}}$ ) than $C 4=0.5$ (red solid lines in Fig. 2c, d). In high wind speed conditions $\left(U_{10}=20\right.$ and $\left.40 \mathrm{~ms}^{-1}\right), C 4=1.0$ underestimates $H_{m 0}$ (overestimates $f_{\mathrm{p}}$ ) more than $C 4=0.5$ in long fetches $(x>10 \mathrm{~km})$.

The effect of the $\ln \left(x^{\prime}\right)^{C 2}$ term can be seen from the comparison between FIT2 and FIT3, the red solid and magenta dashed lines in Fig. 2b, c, d. The impact of $C 2$ to $H_{m 0}$ and $f_{\mathrm{p}}$ is much weaker than $C 4$. Using $C 2=2$ (magenta dashed lines in Fig. 2c, d) results in slightly larger $H_{m 0}$ (smaller $f_{\mathrm{p}}$ ) than $C 2=4$ (red solid lines in Fig. 2c, d) in long fetches $(x>10 \mathrm{~km})$, which results in larger white-capping dissipation, smaller $H_{m 0}$, and larger $f_{\mathrm{p}}$.

FIT1-FIT3 tend to underestimate $H_{m 0}$ (overestimate $f_{\mathrm{p}}$ ) in long fetches $(x>10 \mathrm{~km})$. In the real case study in Sect. 4.3, it will be shown that such an underestimation of 

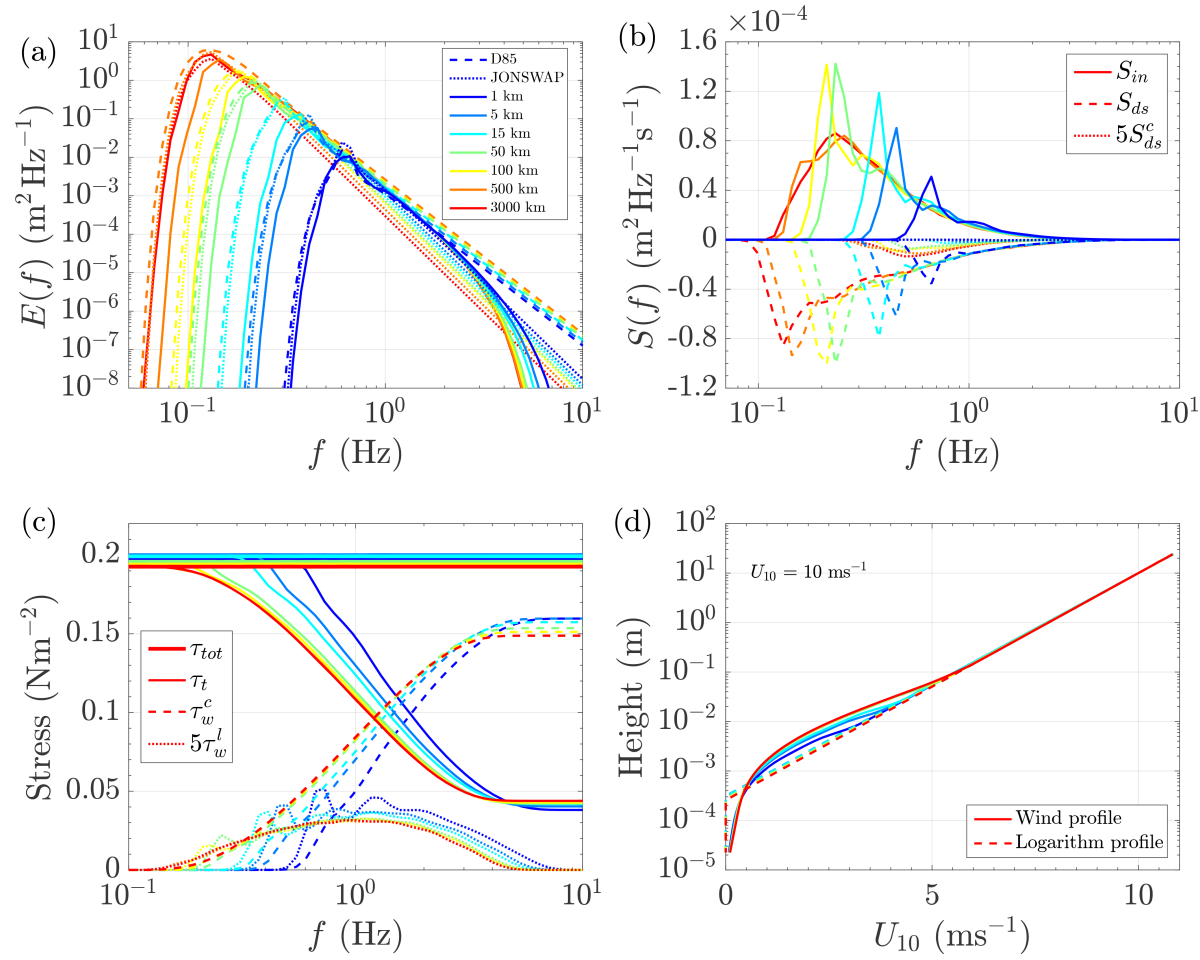

Figure 3. Wave spectrum (a), wind-input and dissipation source terms (b), stress distribution over frequencies (c), and wind profile (d) calculated from WBLM, in $10 \mathrm{~ms}^{-1}$ wind speed conditions at different fetches after $72 \mathrm{~h}$ simulation, in the fetch-limited wave growth study. The dashed lines and dotted lines in panel (a) are the wave spectrum parameterization from D85 (Donelan et al., 1985) and JONSWAP (Hasselmann et al., 1973); the solid lines are from WBLM. The solid, dashed, and dotted lines in panel (b) are the WBLM wind-input ( $S_{\text {in }}$ ), white-capping dissipation $\left(S_{\mathrm{ds}}\right)$, and 5 times the cumulative dissipation $\left(5 S_{\mathrm{ds}}^{\mathrm{c}}\right)$ source functions, respectively. Thick solid, thin solid, dashed, and dotted lines in panel $(\mathbf{c})$ are the total stress $\left(\tau_{\text {tot }}\right)$, turbulent stress $\left(\tau_{\mathrm{t}}\right)$, cumulative wave-induced stress $\left(\tau_{\mathrm{w}}^{\mathrm{c}}\right)$, and 5 times the local waveinduced stress $\left(5 \tau_{\mathrm{w}}^{1}\right)$ from WBLM. The solid lines in panel (d) are calculated from WBLM, and the dashed lines are the relative logarithm wind profiles extended from wind speed at $10 \mathrm{~m}$ elevation.

$H_{m 0}$ failed in capturing large waves in real storm simulations. Therefore, we continuously reduce the value of $C 2$ and $C 4$ until the large waves are captured in both the idealized fetchlimited study and real case study, which results in the parameters of FIT4 (hereafter WBLM). In FIT4, $C 4=0.0$ means that $\left(\frac{U^{\prime}}{10}\right)$ term is disappeared in Eq. (22). From Eq. (17), we found that both $U^{\prime}$ and $x^{\prime}$ could be written in the form of $A_{1} m_{0}^{A_{2}} f_{\mathrm{p}}^{A_{3}}$, which indicate that the function of the $U^{\prime}$ term could be replaced by changing the parameters in the $x^{\prime}$ term. This can be seen from the green lines in Fig. $2 b$ that, without the $\left(\frac{U^{\prime}}{10}\right)$ term, $C_{\mathrm{ds}}$ still follows different curves in different wind speed conditions.

Figure 3a shows the wave spectrum from WBLM (solid lines) in $10 \mathrm{~ms}^{-1}$ wind speed conditions after $72 \mathrm{~h}$ simulation in comparison to the spectrum parameterization of D85 (Donelan et al., 1985) (dashed lines) and JONSWAP (Hasselmann et al., 1973) (dotted lines) with the fetch dependence from Kahma and Calkoen (1992). Detailed equations for D85 and JONSWAP are listed in Appendix A. The results from the WBLM source term generally follow the shape of the
D85 and JONSWAP spectra, but they tend to underestimate the energy at low frequencies at fetches $x \geq 10 \mathrm{~km}$.

The D85 spectra at short fetches (e.g., $1 \mathrm{~km}$ ) have less energy at high frequencies (e.g., $f>1 \mathrm{~Hz}$ ) than at long fetches (e.g., $3000 \mathrm{~km}$ ). On the contrary, JONSWAP and WBLM spectra have more energy at short fetches than at long fetches at high frequencies. The D85 spectra have a $f^{-4}$ shape at high frequencies, while JONSWAP has a $f^{-5}$ shape. The high-frequency part of WBLM spectra is between $f^{-4}$ and $f^{-5}$. Figure $3 \mathrm{~b}$ shows the source term distribution of wind-input ( $S_{\mathrm{in}}$, solid lines), white-capping dissipation $\left(S_{\mathrm{ds}}\right.$, dashed lines), and 5 times the cumulative dissipation $\left(5 S_{\mathrm{ds}}^{\mathrm{c}}\right.$, dotted lines) source functions at different fetches indicated by color legends in Fig. 3a. $5 S_{\mathrm{ds}}^{\mathrm{c}}$ instead of $S_{\mathrm{ds}}^{\mathrm{c}}$ is used to better visualize the cumulative dissipation source term. As the waves grow older, the $S_{\text {in }}$ values at high frequencies become smaller, and $S_{\mathrm{ds}}^{\mathrm{c}}$ values become larger, which may explain why the WBLM spectra have more energy at short fetches than at long fetches at high frequencies. Figure $3 \mathrm{c}$ shows the corresponding stress distribution within the wave boundary layer. Here, we also use $5 \tau_{\mathrm{w}}^{1}$ (dotted lines) instead 


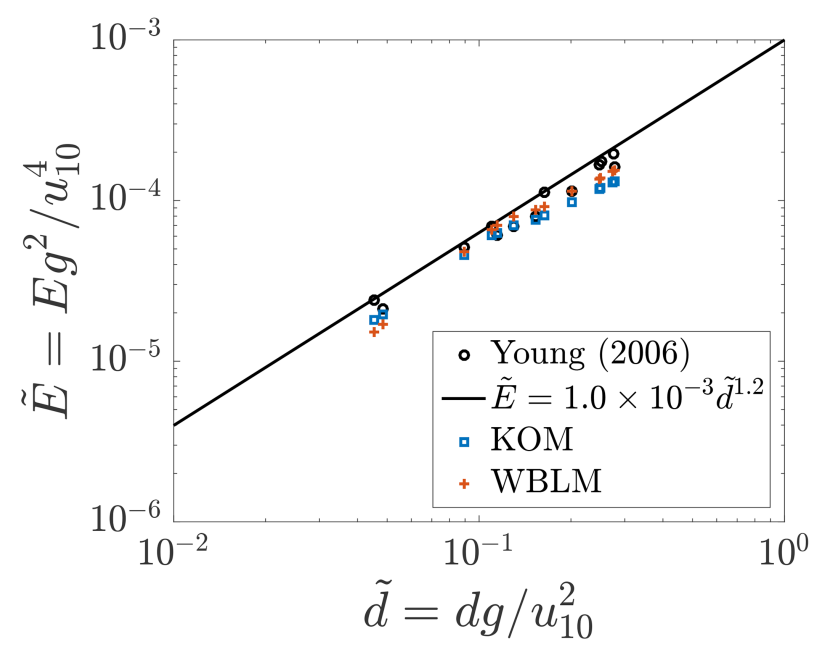

Figure 4. Observed (black circles) and parameterized (black line) non-dimensional wave energy for fully developed waves in shallow water as a function of non-dimensional depth (Young and Babanin, 2006b) and SWAN results with KOM (blue squares) and WBLM (red crosses) source terms after $24 \mathrm{~h}$ simulation.

of $\tau_{\mathrm{w}}^{1}$ for the purpose of visualizing the local wave-induced stress. Short fetch waves contribute more surface stress than long fetch waves at high frequencies, while they contribute less stress than long fetch waves at low frequencies. The total wave-induced stress depends on the integration of $\tau_{\mathrm{w}}^{1}$ at all frequencies, which results in waves with a fetch of 5$15 \mathrm{~km}$ having the highest total wave-induced stress, waves with a fetch of $1 \mathrm{~km}$ having lower total wave-induced stress, and waves with a fetch of $3000 \mathrm{~km}$ having the lowest waveinduced stress. Accordingly, total wind stress ( $\tau_{\text {tot }}$, thick solid lines) at $5-15 \mathrm{~km}$ is larger than that at 1 and $3000 \mathrm{~km}$ because of the impact of the waves. Figure $3 \mathrm{~d}$ shows the wind profiles within the wave boundary layer calculated by WBLM. Wind profiles are rather different in different wave development stages, which reveals that it is necessary to take the waveinduced wind profile variation into account in the estimation of the critical height in Sect. 2.1.

\subsection{Idealized depth-limited study}

Figure 4 shows the non-dimensional wave energy as a function of non-dimensional depth for fully developed waves in shallow waters after $24 \mathrm{~h}$ simulation, with the measurements of Young and Babanin (2006b) as reference. In comparison, results from KOM source terms are also shown. Both the WBLM (red crosses) and KOM (blue squares) show close agreement with the measurements (black circles).

The one-dimensional wave spectrum in the depth-limited experiment is further examined after $24 \mathrm{~h}$ simulation in Fig. 5a-e for different wind speed and depth conditions, with the measurements of Young and Babanin (2006b) as reference. Both models capture the peak of the wave spectrum. However, KOM (blue lines) tends to underestimate the en- ergy level at high frequencies. On the contrary, the energy level of WBLM (red lines) at high frequencies closely follows the measurements.

\subsection{Two storms during the RUNE project}

During the two RUNE storms on 28 November 2015 and 12 August 2015, wave simulation was done with SWAN forced by CFSv2 wind. The performance of KOM, JANS, and WBLM source terms are evaluated with buoy measurements in terms of significant wave height $H_{m 0}$, mean wave direction $D_{\text {mean }}$, peak period $T_{\mathrm{p}}$, mean period $T_{m 01}$, and onedimensional wave spectrum. Figure 6 shows the simulated time series of $H_{m 0}, D_{\text {mean }}, T_{\mathrm{p}}$, and $T_{m 01}$ in comparison to buoy measurements at RUNE. To see the impact of different parameters of the WBLM white-capping dissipation source function to the wave simulation, results from FIT1 to FIT3 are also shown. Similar to the conclusions in the idealized fetch-limited study in Sect. 4.1, these parameters significantly underestimate high waves. Only FIT4 (here WBLM) can be used for real wave simulations to capture the high waves.

Now we compare the performance of the new WBLM with KOM and JANS source terms. For $H_{m 0}, D_{\text {mean }}$, and $T_{\mathrm{p}}$, all the modeled time series generally follow the general trends of measurement data. The biggest error of $H_{m 0}$ happens at the two storm peaks. The three source terms overestimate the $H_{m 0}$ during the peak at about $1 \mathrm{~m}(15 \%)$. WBLM gives slightly better $H_{m 0}$ during the peak than KOM and JANS. But it tends to underestimate $T_{\mathrm{p}}$ during the storm peaks. WBLM predicts $T_{m 01}$ significantly better than KOM and JANS. Note that the buoy $T_{m 01}$ is calculated from the frequency range of 0.005 to $0.64 \mathrm{~Hz}$, JANS is from 0.03 to $0.58 \mathrm{~Hz}$, and KOM and WBLM are from 0.03 to $0.63 \mathrm{~Hz}$. A summary of the statistics is listed in Table 5, and the definitions of the statistics are given in Appendix B. WBLM generally provides better results for $H_{m 0}$ and $T_{m 01}$ than KOM and JANS. All the three source terms have similar accuracy in predicting $D_{\text {mean }}$. WBLM is slightly less accurate in predicting $T_{\mathrm{p}}$ than KOM and JANS.

The time series of $H_{m 0}$ at another nine measurement sites, including Fjaltring (FG), Hanstholm (HM), A121 (A1), Väderöarna (VA), Heligoland north (HN), Fino-1 (F1), Fino3 (F3), Sleipner-A (SA), and Ekofisk (EK) in the North Sea during the two storm simulations, are shown in Fig. 7. The relative statistics are listed in Table 6. Considering the statistics of mean difference (bias), root mean square error (RMSE), and scatter index (SI), WBLM generally gives better $H_{m 0}$ than KOM and JANS for most of the sites. However, in contrast to RUNE, WBLM tends to underestimate the largest waves during storm peaks in the open-ocean sites, e.g., the storm peak at A121 (Fig. 7c), Sleipner-A (Fig. 7g), and Ekofisk (Fig. 7i).

The one-dimensional wave spectrum during the whole simulation period at the RUNE site is presented in Fig. 8. 
(a)

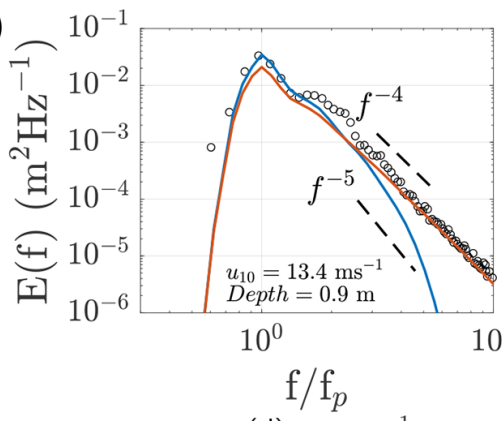

(d)

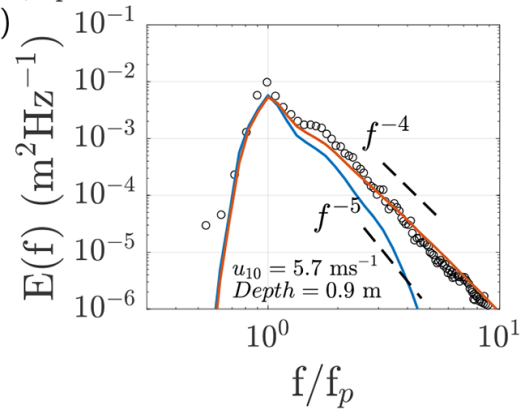

(b)

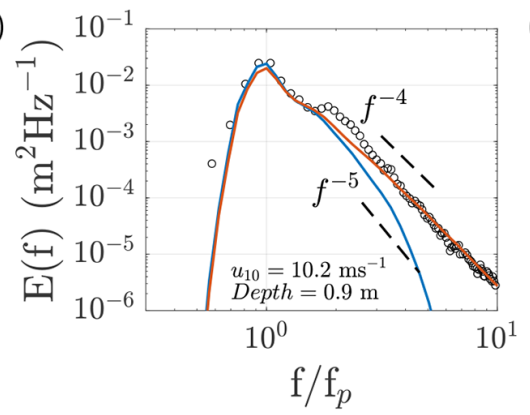

(c)

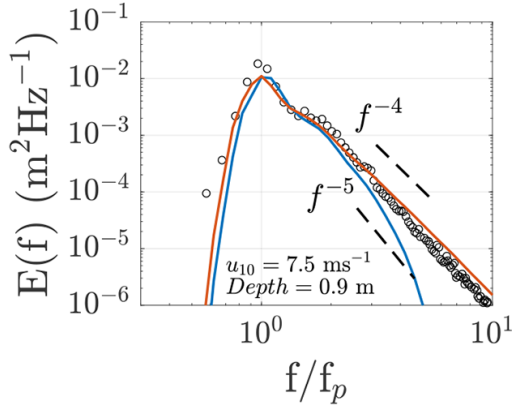

(e)

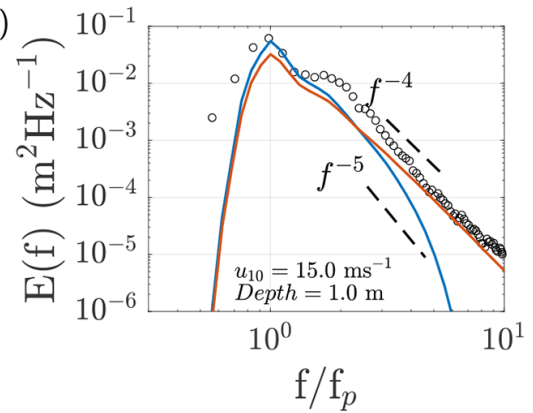

Figure 5. One-dimensional wave spectrum measured by (Young and Babanin, 2006b) (black circles) for fully developed waves in shallow water and the results from SWAN with KOM (blue lines) and WBLM (red lines) source functions after $24 \mathrm{~h}$ simulation.

Table 5. Statistics of simulated significant wave height $\left(H_{m 0}\right)$, mean wave direction $\left(D_{\text {mean }}\right)$, and peak $\left(T_{\mathrm{p}}\right)$ and mean $\left(T_{m 01}\right)$ wave period in comparison to buoy measurements at the RUNE site on 28 November 2015 and 12 August 2015. The statistics include mean difference (bias), root mean square error (RMSE), and scatter index (SI). In each column, the values of smallest absolute errors are indicated with bold text.

\begin{tabular}{|c|c|c|c|c|c|c|c|c|c|c|c|c|}
\hline \multirow{2}{*}{ Exp. } & \multicolumn{3}{|c|}{$H_{m 0}(\mathrm{~m})$} & \multicolumn{3}{|c|}{$D_{\text {mean }}\left({ }^{\circ}\right)$} & \multicolumn{3}{|c|}{$T_{\mathrm{p}}(\mathrm{s})$} & \multicolumn{3}{|c|}{$T_{m 01}$} \\
\hline & Bias & RMSE & SI & Bias & RMSE & SI & Bias & RMSE & SI & Bias & RMSE & SI \\
\hline KOM & 0.24 & 0 & 0. & נונ. & 8.3 & 0.0 & 0.25 & 1.2 & 0.13 & 1.60 & 1.74 & 0.11 \\
\hline JANS & 0.17 & 0.52 & 0.15 & 3.40 & 8.74 & 0.03 & 0.23 & 1.36 & 0.14 & 1.56 & 1.71 & 0.11 \\
\hline WBLM & 0.35 & 0.52 & 0.12 & 2.98 & 8.84 & 0.03 & -0.13 & 1.44 & 0.15 & 0.57 & 0.67 & 0.06 \\
\hline
\end{tabular}

The colored lines in Fig. 8a show the data from buoy measurements, and the black envelope lines are used to mark the upper and lower bounds of the measurement data. The colored lines in Fig. 8b, c, d are from SWAN simulations using KOM, JANS, and WBLM source terms, and the black envelope lines are the same as those in Fig. 8a. The three simulations generally capture the shape of the measured spectrum. In comparison to the measurements, KOM and JANS tend to overestimate the energy around the spectral peak, while WBLM gives better energy estimation around the spectral peak. Both KOM and JANS show a leveling off of energy at frequencies higher than about $0.3 \mathrm{~Hz}$, while the measurement and WBLM do not, which may explain the failure of KOM and JANS in simulating $T_{m 01}$. However, seemingly WBLM tends to overestimate the energy at frequencies higher than the peak, which needs further investigation.

\section{Discussion}

This study first calibrates the WBLM wind-input and dissipation source terms in idealized fetch-limited cases and further validates the model in idealized depth-limited cases and two real storm cases. In the selected cases, it is proven that the revised WBLM source terms can be used for real cases and can provide certain wave properties better than the original ones in SWAN, such as KOM and JANS. However, two storm cases do not represent all the wave conditions in the ocean; e.g., bimodal waves, slant waves, and swells are not analyzed in detail in this study. Therefore, more comprehensive analysis and validations from different data resources such as satellite data are still necessary in further studies.

The main difference between WBLM and previous windinput source functions in SWAN is that the WBLM explicitly considers physics such as the growth rate reduction of short wind waves in the presence of long waves. This effect mainly affect the young waves. Moreover, the modification of the 

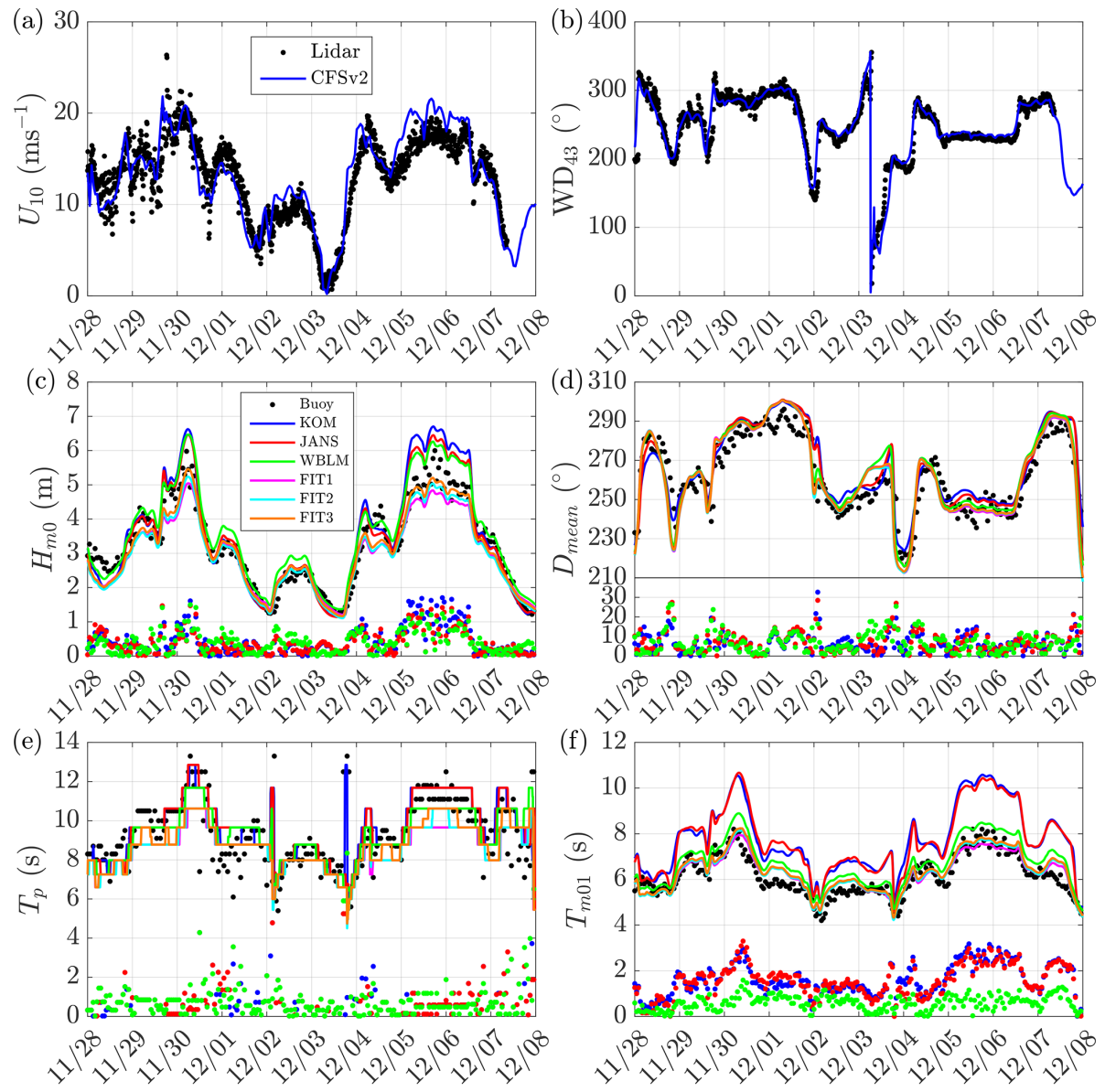

2015

2015

Figure 6. Time series during two winter storms in the RUNE project. (a) The $10 \mathrm{~m}$ wind speed from CFSv2 and measurements calculated from a logarithm wind profile from lidar measurements at 43, 50, 62, 82, and $100 \mathrm{~m}$. (b) Wind direction from CFSv2 and lidar measurement at $43 \mathrm{~m}$. (c) Modeled significant wave height (solid lines) in comparison to buoy measurements (black dots); colored dots show the absolute error. (d) Mean wave direction. (e) Peak wave period. (f) Mean wave period.

Table 6. Statistics of simulated significant wave height $\left(H_{m 0}\right)$ in comparison to measurements at Fjaltring (FG), Hanstholm $(\mathrm{HM})$, A121 (A1), Väderöarna (VA), Heligoland north (HN), Fino-1 (F1), Fino-3 (F3), Sleipner-A (SA), and Ekofisk (EK) on 28 November 2015 and 12 August 2015. The statistics include mean difference (bias), root mean square error (RMSE), and scatter index (SI). In each column, the values of smallest absolute errors are indicated with bold text.

\begin{tabular}{lrrrrrrrrrr}
\hline \multirow{2}{*}{ Statistics } & Exp. & FG & HM & SA & EK & F1 & F3 & A1 & VA & HN \\
\hline \multirow{3}{*}{ Bias } & KOM & $\mathbf{0 . 0 1}$ & -0.07 & $-\mathbf{0 . 1 2}$ & -0.12 & 0.06 & $-\mathbf{0 . 0 1}$ & -0.14 & -0.25 & -0.15 \\
& JANS & -0.06 & -0.08 & -0.27 & -0.12 & $\mathbf{0 . 0 2}$ & -0.08 & -0.22 & -0.32 & -0.26 \\
& WBLM & 0.13 & $\mathbf{0 . 0 0}$ & -0.19 & $-\mathbf{0 . 0 6}$ & 0.09 & $-\mathbf{0 . 0 1}$ & $-\mathbf{0 . 0 8}$ & $-\mathbf{0 . 1 1}$ & $-\mathbf{0 . 1 3}$ \\
\hline \multirow{3}{*}{ RMSE } & KOM & 0.64 & 0.54 & $\mathbf{0 . 5 1}$ & 0.54 & 0.49 & 0.51 & 0.47 & 0.69 & 0.60 \\
& JANS & 0.57 & 0.52 & 0.56 & 0.60 & 0.51 & 0.54 & 0.48 & 0.72 & 0.66 \\
& WBLM & $\mathbf{0 . 5 1}$ & $\mathbf{0 . 4 3}$ & 0.52 & $\mathbf{0 . 5 3}$ & $\mathbf{0 . 3 7}$ & $\mathbf{0 . 4 1}$ & $\mathbf{0 . 3 6}$ & $\mathbf{0 . 6 7}$ & $\mathbf{0 . 5 7}$ \\
\multirow{3}{*}{ SI } & KOM & 0.19 & 0.20 & $\mathbf{0 . 1 4}$ & $\mathbf{0 . 1 7}$ & 0.17 & 0.17 & 0.13 & $\mathbf{0 . 1 7}$ & 0.16 \\
& JANS & 0.17 & 0.20 & $\mathbf{0 . 1 4}$ & 0.19 & 0.18 & 0.18 & 0.12 & $\mathbf{0 . 1 7}$ & 0.17 \\
& WBLM & $\mathbf{0 . 1 4}$ & $\mathbf{0 . 1 7}$ & $\mathbf{0 . 1 4}$ & $\mathbf{0 . 1 7}$ & $\mathbf{0 . 1 3}$ & $\mathbf{0 . 1 4}$ & $\mathbf{0 . 1 0}$ & $\mathbf{0 . 1 7}$ & $\mathbf{0 . 1 5}$
\end{tabular}



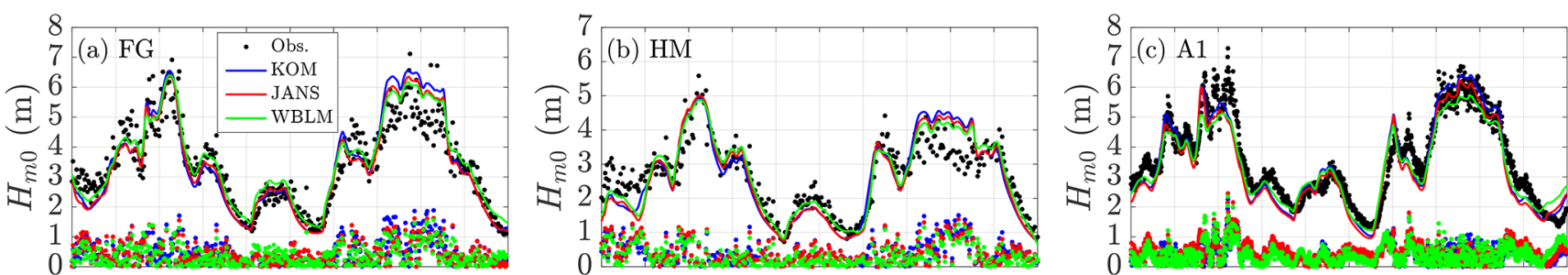

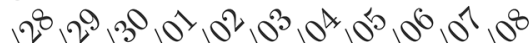

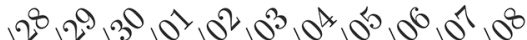

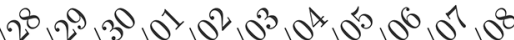

जौञ

त्रतथ

त1 $12,2,2,2,2,2,2,2$
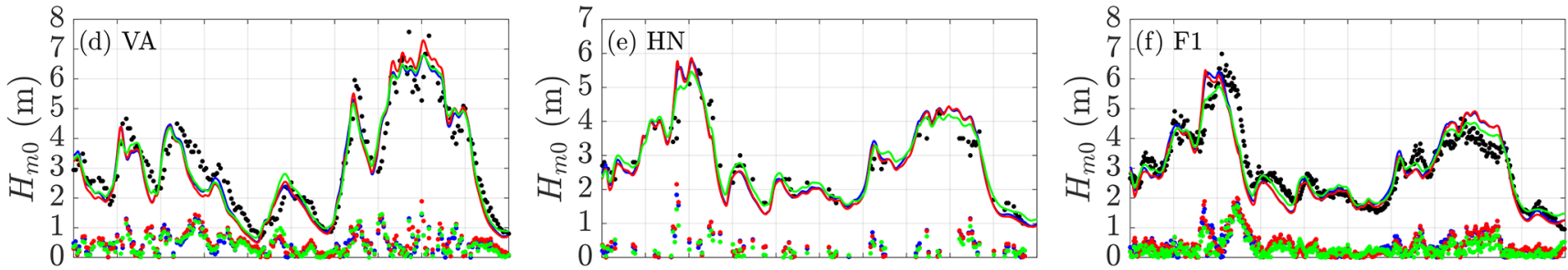

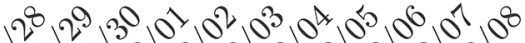

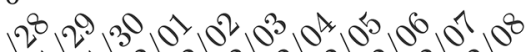

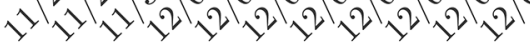

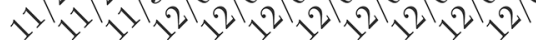

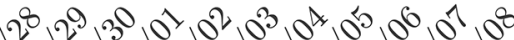

तो $1,2,2,2,2,2,2,2$
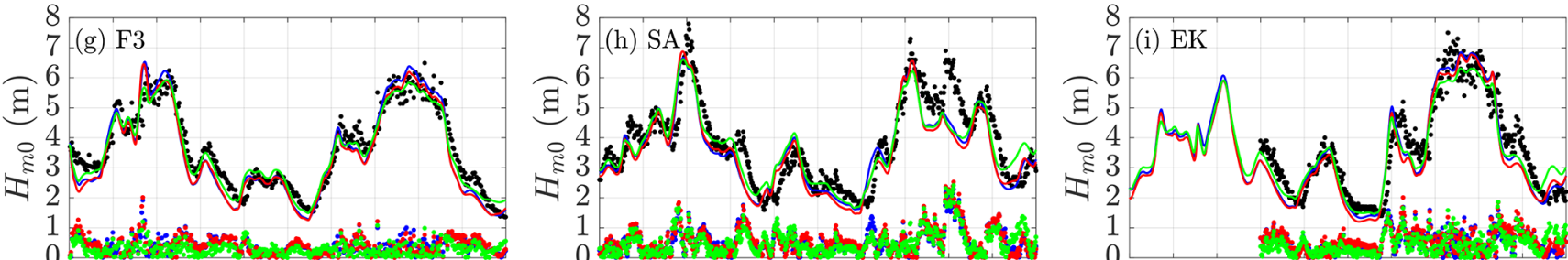

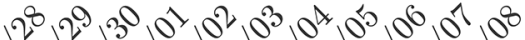

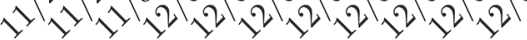

2015

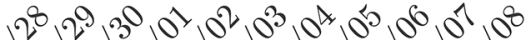

11, $12,2,2,2,2,2,2$

2015

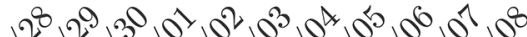

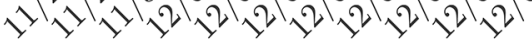

2015

Figure 7. Time series of $H_{m 0}$ at Fjaltring (FG), Hanstholm (HM), A121 (A1), Väderöarna (VA), Heligoland north (HN), Fino-1 (F1), Fino-3 (F3), Sleipner-A (SA), and Ekofisk (EK) during the two winter storms in the RUNE project. Observations are shown in black dots, modeled $H_{m 0}$ using different source terms are shown in colored solid lines, and the corresponding colored dots show the absolute error between modeled results and observations.
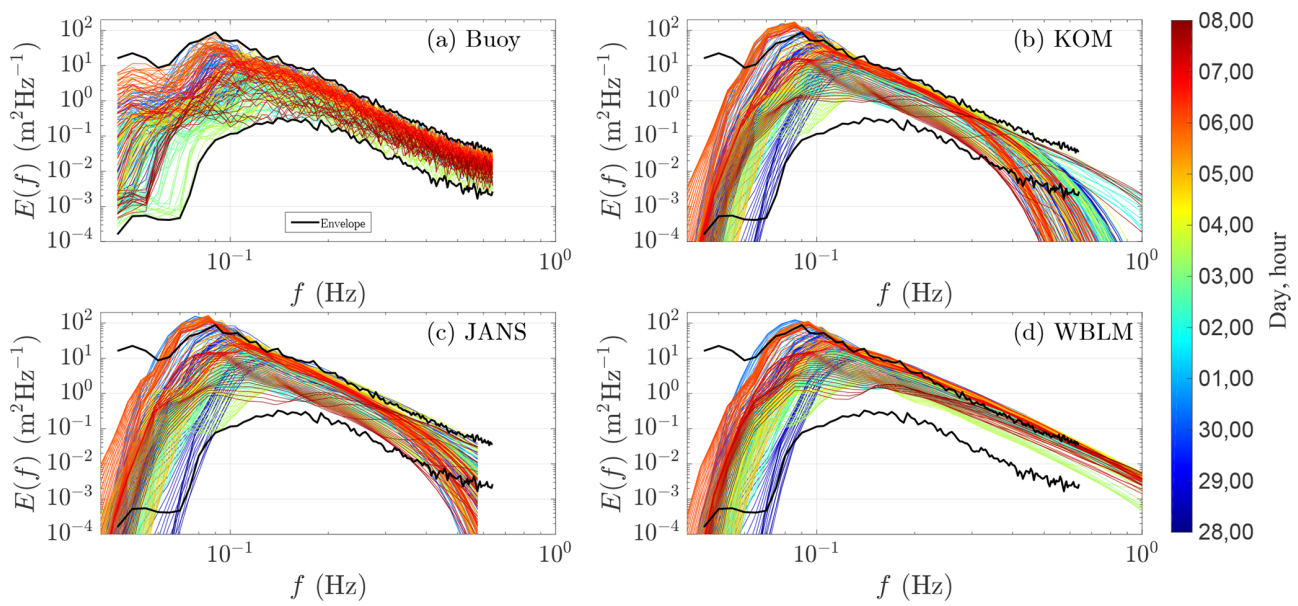

Figure 8. One-dimensional wave spectrum from buoy measurements at RUNE with all available data during the two storms (a); panels (bd) are simulated with different source terms. The colors of the lines represent different times. The black solid lines in each panel are the envelope lines to mark the upper and lower bounds of the measurement data. 
dissipation coefficient is also focused on the young wind waves. Therefore, the introduction of WBLM source terms to SWAN mainly improves the young wind waves which are usually found in the coastal areas. This can be seen in Fig. 7. The significant wave height $\left(H_{m 0}\right)$ at the storm peak at the open-sea sites, including A121 (Fig. 7c), Sleipner-A (Fig. 7h), and Ekofisk (Fig. 7i), is underestimated by WBLM in comparison to measurements, while at the other coastal sites, the $H_{m 0}$ at the storm peak is captured quite well by WBLM. Relating the underestimation of $H_{m 0}$ at the storm peak at the open-sea sites and the underestimation of $T_{\mathrm{p}}$ at RUNE (Fig. 6e), these defects maybe due to the inaccuracy of the calculation of nonlinear four-wave interactions at low frequencies or the overestimation of swell dissipation. Here, we simply added a positive wave age tuning parameter $\alpha$ in Eq. (11) following Bidlot et al. (2007) to shift the wave growth towards a lower frequency, which may not enough to overcome these defects. A more exact method for the calculation of nonlinear four-wave interactions and an independent swell dissipation such as that used by Ardhuin et al. (2010) is needed in the future study.

As mentioned in Du et al. (2017), one of the biggest strengths of WBLM is in the estimation of the air-sea momentum flux. Since this study mainly concerns its behavior in the wave simulations, the air-sea momentum flux (or roughness length/drag coefficient) is not included in the analysis. A future study with the focus on its momentum flux estimation was carried out and presented in Du (2017) chap. 8, and it was found that the WBLM method provides reliable roughness length estimation in terms of the magnitude and the spatial distribution of it in coastal shallow water in comparison to point measurements and the Envisat Advanced Synthetic Aperture Radar (ASAR) backscatter.

The WBLM source terms is found to improve the prediction of the mean period significantly. Through analyzing the frequency spectra, it is speculated to be caused by an improved description of the high-frequency part of the spectrum. However, the energy from WBLM at high frequencies seems too high in comparison to measurements. Therefore, the energy distribution in the high-frequency range needs to be further investigated. One possible way of reducing this overestimated energy at high frequencies is by tuning the parameters in the cumulative dissipation source function (e.g., $C_{\mathrm{cu}}$ in Eq. 19). However, the tuning of these parameters has to be followed by the tuning of the other parameters in the source terms including wind-input, white-capping, nonlinear four-wave interactions, etc. to make sure that both the stress estimation and the wave simulation are all satisfied.

Janssen (1991)'s wind-input source function was found by Du et al. (2017) and Du (2017) chap. 5 to be wrongly implemented in SWAN. We found that in the calculation of the contribution of high-frequency tail to wave stress code, the judgment of whether the growth rate coefficient of a frequency $\left(\beta_{\mathrm{g}}\right)$ over all directions is zero, is called before calculating $\beta_{\mathrm{g}}$ in all the directions. This may disregard some of the high-frequency waves and therefore reduces the calculated wave stress. We also tried our best to change the code following the description of Bidlot et al. (2007) and by implementing some functions from WAM code (https: //github.com/mywave/WAM, last access: 21 June 2017) to SWAN. Since this study is mainly focused on the usage of WBLM, a detailed analysis of Janssen implementation in SWAN is out of the scope of this paper.

\section{Conclusions}

This study aims at applying the WBLM source functions of Du et al. (2017) in SWAN for real wave simulations. Several improvements on the WBLM wind-input and white-capping dissipation source functions are realized. Firstly, the WBLM wind-input source function is modified by considering the wind profile change in the estimation of the non-dimensional critical height. Secondly, a revised white-capping dissipation source function is applied, which enables the WBLM method to be used for varying wind conditions. Thirdly, a few refinements of the numerical algorithms of WBLM in SWAN are done to improve the model stability and efficiency, which make it possible to be used for large-domain and high-resolution simulations.

The new pair of WBLM wind-input and dissipation source functions is calibrated with fetch-limited and depth-limited simulations. It is proven to be able to reproduce the benchmark wave growth curve of Kahma and Calkoen (1992), the energy level, and the one-dimensional wave spectrum measured by Young and Babanin (2006b) in the depth-limited study.

The WBLM wind-input and dissipation source functions are validated with several point measurements during two storms over the North Sea. Results show that, in comparison to the original wind-input and dissipation source functions in SWAN, namely Komen et al. (1984) and Janssen (1991), WBLM improves the prediction of significant wave height and mean wave period in comparison to measurements.

Code and data availability. The source code for SWAN used in this study is freely available at http://swanmodel.sourceforge.net (last access: 21 June 2017). The bathymetry data is obtained from EMODnet (http://www.emodnet-bathymetry.eu/, last access: 20 November 2014). The observational wave data is downloaded from NOOS (https://noos.bsh.de/, last access: 15 June 2017), FINO (http://fino.bsh.de, registration needed, last access: 3 April 2018), and eKlima (http://sharki.oslo.dnmi.no, registration needed, last access: 17 November 2016). CFSv2 $10 \mathrm{~m}$ wind speed is download from NCEP Climate Forecast System Version 2 (CFSv2) Selected Hourly Time-Series Products (Saha et al., 2011). The model data and source code modifications can be obtained from the corresponding author. 


\section{Appendix A: D85 and JONSWAP spectra}

The D85 (Donelan et al., 1985) spectra are described by

$$
\begin{aligned}
E(f) & =\alpha_{D} \frac{g^{2}}{(2 \pi)^{4}} f_{\mathrm{p}}^{-1} f^{-4} \exp \\
& {\left[-\left(\frac{f}{f_{\mathrm{p}}}\right)^{-4}\right] \cdot \gamma_{D} \exp \left[\frac{-\left(f-f_{\mathrm{p}}\right)^{2}}{2 \sigma_{D}^{2} f_{\mathrm{p}}^{2}}\right], }
\end{aligned}
$$

where $f$ is the frequency and $f_{\mathrm{p}}$ is the frequency at the spectral peak. $\alpha_{D}$ is a equilibrium range parameter which is written as

$\alpha_{D}=0.006\left(\frac{U_{10}}{c_{\mathrm{p}}}\right)^{0.55}$,

where $U_{10}$ is $10 \mathrm{~m}$ wind speed. $c_{\mathrm{p}}$ is the phase velocity at the spectral peak. In deep water conditions, $c_{\mathrm{p}}=\frac{g}{2 \pi f_{\mathrm{p}}}$, where $g$ is the gravity acceleration. $\gamma_{D}$ is a peak enhancement factor:

$\gamma_{D}=\operatorname{MAX}\left[1.7+6.0 \log \left(\frac{U_{10}}{c_{\mathrm{p}}}\right), 1.7\right]$,

and $\sigma_{D}$ is a peak width parameter, which is written as

$\sigma_{D}=0.008\left[1+4\left(\frac{U_{10}}{c_{\mathrm{p}}}\right)^{-3}\right]$.

The JONSWAP (Hasselmann et al., 1973) spectra are described by

$$
\begin{aligned}
& E(f)=\alpha_{J} \frac{g^{2}}{(2 \pi)^{4}} f^{-5} \exp \\
& {\left[-\frac{5}{4}\left(\frac{f}{f_{\mathrm{p}}}\right)^{-4}\right] \cdot \gamma_{J}{ }^{\exp \left[\frac{-\left(f-f_{\mathrm{p}}\right)^{2}}{2 \sigma_{J}^{2} f_{\mathrm{p}}^{2}}\right],}}
\end{aligned}
$$

where the equilibrium range parameter is written as

$\alpha_{J}=0.076 \widetilde{x}^{-0.22}$,

where $\left(\widetilde{x}=x g / U_{10}^{2}\right)$ is a non-dimensional fetch, and $x$ is the fetch. Parameterization for the peak enhancement factor $\left(\gamma_{J}\right)$ for JONSWAP spectra is not provided by Hasselmann et al. (1973). According to Hasselmann et al. (1973), $\gamma_{J}$ is scatted between 1.5 and 6.0, with an average value of 3.3. So, we use the same equation as D85 (Eq. A3) with a limit of $1.5 \leq$ $\gamma_{J} \leq 6.0$. The peak width parameter is written as

$\sigma_{J}=\left\{\begin{array}{l}0.07 ; f<f_{\mathrm{p}} \\ 0.09 ; f \geq f_{\mathrm{p}} .\end{array}\right.$

For both D85 and JONSWAP spectra, the peak frequency $\left(f_{\mathrm{p}}\right)$ for a given wind speed $\left(U_{10}\right)$ and fetch $(x)$ is calculated from the fetch-limited wave growth relationship of Kahma and Calkoen (1992):

$f_{\mathrm{p}}=2.1804 \tilde{x}^{-0.27} \cdot \frac{g}{U_{10}}$.

\section{Appendix B: Definition of statistics}

Taking $X$ as the observation value and $Y$ as the modeled value, the mean difference is defined as

$\operatorname{Bias}=\frac{1}{N} \sum_{i=1}^{N}(Y-X)_{i}$.

The root mean square error is defined as

$\mathrm{RMSE}=\sqrt{\frac{1}{N} \sum_{i=1}^{N}(Y-X)_{i}^{2} .}$

The scatter index is defined as

$\mathrm{SI}=\frac{\sqrt{\frac{1}{N} \sum_{i=1}^{N}(Y-X-\text { bias })_{i}^{2}}}{\frac{1}{N} \sum_{i=1}^{N}\left|X_{i}\right|}$. 
Author contributions. The updated WBLM model was developed by JD. JD, RB, and XGL designed all the numerical experiments, which where performed by JD. RB provided the measurement data of RUNE. The manuscript was written by JD with the assistance of $\mathrm{RB}, \mathrm{XGL}$, and MK. All authors worked on the paper.

Competing interests. The authors declare that they have no conflict of interest.

Special issue statement. This article is part of the special issue "Coastal modelling and uncertainties based on CMEMS products". It is not associated with a conference.

Acknowledgements. This project has received funding from the Danish Forskel project X-WiWa (PSO-12020), the EU CEASELESS project (H2020-EO2016-730030), and the National Key Research and Development Program of China (2017YFC1404200). We are grateful to Jean Raymond Bidlot from ECMWF, Anna Rutgersson from Uppsala University, and Henrik Bredmose from DTU Wind Energy for helpful discussions and inputs. Furthermore, we would like to thank Rogier Floors from DTU Wind Energy for providing the measurement data during Danish ForskEL project RUNE (12263).

Edited by: Manuel Espino Infantes

Reviewed by: one anonymous referee

\section{References}

Alves, J. H. G. M. and Banner, M. L.: Performance of a Saturation-Based Dissipation-Rate Source Term in Modeling the Fetch-Limited Evolution of Wind Waves, J. Phys. Oceanogr., 33, 1274-1298, https://doi.org/10.1175/15200485(2003)033<1274:POASDS>2.0.CO;2, 2003.

Ardhuin, F.: Dissipation parameterizations in spectral wave models and general suggestions for improving on today's wave models Fabrice Ardhuine, in: ECMWF Workshop on Ocean Waves, June, 113-124, 2012.

Ardhuin, F. and Roland, A.: Coastal wave reflection, directional spread, and seismoacoustic noise sources, J. Geophys. Res.-Oceans, 117, 1-16, https://doi.org/10.1029/2011JC007832, 2012.

Ardhuin, F., Rogers, E., Babanin, A. V., Filipot, J.-F., Magne, R., Roland, A., van der Westhuysen, A., Queffeulou, P., Lefevre, J.-M., Aouf, L., and Collard, F.: Semiempirical Dissipation Source Functions for Ocean Waves, Part I: Definition, Calibration, and Validation, J. Phys. Oceanogr., 40, 1917-1941, https://doi.org/10.1175/2010JPO4324.1, 2010.

Ardhuin, F., Roland, A., Dumas, F., Bennis, A.-C., Sentchev, A., Forget, P., Wolf, J., Girard, F., Osuna, P., and Benoit, M.: Numerical wave modelling in conditions with strong currents: dissipation, refraction and relative wind, J. Phys. Oceanogr., 42, https://doi.org/10.1175/JPO-D-11-0220.1, 2012.

Babanin, A. V. and Young, I. R.: Two-phase behaviour of the spectral dissipation of wind waves, in: Proc. Ocean Waves Measure- ments and Analysis, Fifth Intern, Symposium WAVES2005, December 2016, 2005.

Babanin, A. V., Tsagareli, K. N., Young, I. R., and Walker, D. J.: Numerical Investigation of Spectral Evolution of Wind Waves, Part II: Dissipation Term and Evolution Tests, J. Phys. Oceanogr., 40, 667-683, https://doi.org/10.1175/2009JPO4370.1, 2010.

Banner, M. L. and Morison, R. P.: Refined source terms in wind wave models with explicit wave breaking prediction, Part I: Model framework and validation against field data, Ocean Model., 33, 177-189, https://doi.org/10.1016/j.ocemod.2010.01.002, 2010.

Battjes, J. A. and Janssen, J. P. F. M.: Energy loss and set-up due to breaking of random waves, in: Proceedings of 16th International Conference on Coast. Eng., New York, American Society of Civil Engineers, 569-587, https://doi.org/10.1017/CBO9781107415324.004, 1978.

Bidlot, J.-R.: Present Status of Wave Forecasting at ECMWF, in: ECMWF Workshop on Ocean Waves, Shinfield Park, Reading RG2 9AX, United Kingdom, 25-27 June 2012, 2012.

Bidlot, J.-R., Janssen, P. A. E. M., and Abdalla, S.: A revised formulation of ocean wave dissipation and its model impact, ECMWF Technical Memorandum, 509, http:/www.citeulike.org/group/ 11419/article/6354018 (last access: 14 October 2014), 2007.

Bolaños, R.: D3.3 Metocean Conditions and Wave Modelling, Tech. Rep. November, available at: http://orbit.dtu.dk/files/155595377/ D3p3_final.pdf (last access: 10 April 2017), 2016.

Bolaños, R. and Rørbæk, K.: D3.1 Metocean Buoy Deployment, Tech. Rep. November, available at: http://orbit.dtu.dk/files/ 155595376/D3p1_final.pdf, (last access: 10 April 2017), 2016.

Bolaños, R., Larsén, X. G., Petersen, O., Nielsen, J., Kelly, M., Kofoed-Hansen, H., Du, J., Sørensen, O., Larsen, S., Hahmann, A., and Badger, M.: Coupling atmospherere and waves for coastal wind turbine design, Proceedings of the Coast. Eng. Conference, 1-11 January 2014, 2014.

Booij, N., Ris, R., and Holthuijsen, L.: A third-generation wave model for coastal regions, I-Model description and validation, J. Geophys. Res., 104, 7649-7666, https://doi.org/10.1029/98JC02622, 1999.

Cavaleri, L.: Wave Modeling-Missing the Peaks, J. Phys. Oceanogr., 39, 2757-2778, https://doi.org/10.1175/2009JPO4067.1, 2009.

Cavaleri, L., Alves, J. H. G. M., Ardhuin, F., Babanin, A., Banner, M., Belibassakis, K., Benoit, M., Donelan, M., Groeneweg, J., Herbers, T. H. C., Hwang, P., Janssen, P. A. E. M., Janssen, T., Lavrenov, I. V., Magne, R., Monbaliu, J., Onorato, M., Polnikov, V., Resio, D., Rogers, W. E., Sheremet, A., McKee Smith, J., Tolman, H. L., van Vledder, G., Wolf, J., and Young, I.: Wave modelling - The state of the art, Prog. Oceanogr., 75, 603-674, https://doi.org/10.1016/j.pocean.2007.05.005, 2007.

Donelan, M. A., Hamilton, J., and Hui, W. H.: Directional Spectra of Wind-Generated Waves, Philos. T. R. Soc. Lond., 315, 509562, https://doi.org/10.1098/rsta.1985.0054, 1985.

Du, J.: Coupling atmospheric and ocean wave models for storm simulation, $\mathrm{Ph} . \mathrm{D}$. thesis, Technical University of Denmark, https://doi.org/10.11581/DTU:00000020, 136 pp., 2017.

Du, J., Bolaños, R., and Larsén, X.: The use of a wave boundary layer model in SWAN, J. Geophys. Res.-Oceans, 122, 42-62, https://doi.org/10.1002/2016JC012104, 2017. 
Floors, R., Hahmann, A., Peña, A., and Karagali, I.: Estimating near-shore wind resources E-Report DTU Wind Energy, Vol. 0116, available at: http://orbit.dtu.dk/files/126992882/final. pdf (last access: 10 April 2017), 2016a.

Floors, R., Lea, G., Peña, A., Karagali, I., and Ahsbahs, T.: Report on RUNE's coastal experiment and first intercomparisons between measurements systems, Vol. 0115, available at: http://orbit.dtu.dk/files/127277148/final.pdf (last access: 10 April 2017), 2016b.

Floors, R., Peña, A., Lea, G., Vasiljevic, N., Simon, E., and Courtney, M.: The RUNE experiment-A database of remotesensing observations of near-shore winds, Remote Sens., 8, https://doi.org/10.3390/rs8110884, 2016c.

Hasselmann, K.: On the spectral dissipation of ocean waves due to white capping, Bound-Lay. Meteorol., 6, 107-127, https://doi.org/10.1007/BF00232479, 1974.

Hasselmann, K., Barnett, T. P., Bouws, E., Carlson, H., Cartwright, D. E., Enke, K., Ewing, J. A., Gienapp, H., Hasselmann, D. E., Kruseman, P., Meerburg, A., Muller, P., Olbers, D. J., Richter, K., Sell, W., and Walden, H.: Measurements of Wind-Wave Growth and Swell Decay during the Joint North Sea Wave Project (JONSWAP), Ergänzungsheft zur Deutschen Hydrographischen Zeitschrift Reihe, A8, p. 95, 2710264, 1973.

Hua, F. and Yuan, Y.: Theoretical Study of Breaking Wave Spectrum and its Application, in: Breaking Waves, Springer Berlin Heidelberg, Berlin, Heidelberg, 277-282, https://doi.org/10.1007/9783-642-84847-6-30, 1992.

Janssen, P. A. E. M.: Quasi-linear Theory of Wind-Wave Generation Applied to Wave Forecasting, J. Phys. Oceanogr., 21, 1631-1642, https://doi.org/10.1175/15200485(1991)021<1631:QLTOWW>2.0.CO;2, 1991.

Kahma, K. K. and Calkoen, C. J.: Reconciling Discrepancies in the Observed Growth of Windgenerated Waves, 22, https://doi.org/10.1175/15200485(1992)022<1389:RDITOG>2.0.CO;2, 1992.

Komen, G. J., Hasselmann, S., and Hasselmann, K.: On the Existence of a Fully Developed Wind-Sea Spectrum, J. Phys. Oceanogr., 14, 1271-1285, https://doi.org/10.1175/15200485(1984)014<1271:OTEOAF>2.0.CO;2, 1984.

Komen, G. J., Cavareli, L., Donelan, M., Hasselmann, K., Hasselmann, S., and Janssen, P. A. E. M.: Dynamics and modelling of ocean waves, Cambridge University Press, https://doi.org/10.1017/CBO9780511628955, 532 pp., 1994.

Larsén, X. G., Du, J., Bolaños, R., and Larsen, S.: On the impact of wind on the development of wave field during storm Britta, Ocean Dynam., 67, 1407-1427, https://doi.org/10.1007/s10236017-1100-1, 2017.

Leckler, F., Ardhuin, F., Filipot, J. F., and Mironov, A.: Dissipation source terms and whitecap statistics, Ocean Model., 70, 62-74, https://doi.org/10.1016/j.ocemod.2013.03.007, 2013.

Longuet-Higgins, M. S.: On Wave Breaking and the Equilibrium Spectrum of Wind-Generated Waves, P. Roy. Soc. A-Math. Phy., 310, 151-159, https://doi.org/10.1098/rspa.1969.0069, 1969.

Melville, W. K. and Matusov, P.: Distribution of breaking waves at the ocean surface., Nature, 417, 58-63, https://doi.org/10.1038/417058a, 2002.

Miles, J. W.: On the generation of surface waves by shear flows, Part 2, J. Fluid Mech., 3, 568-582, https://doi.org/10.1017/S0022112059000830, 1957.
Phillips, O. M.: Spectral and statistical properties of the equilibrium range in wind-generated gravity waves, J. Fluid Mech., 156, 505531, https://doi.org/10.1017/S0022112085002221, 1985.

Polnikov, V. G.: On a description of a wind-wave energy dissipation function, in: The Air-Sea Interface: Radio and Acoustic Sensing, Turbulence and Wave Dynamics, edited by: Donelan, M. A., Hui, W. H., and Plant, W. J., Rosenstiel School of Marine and Atmospheric Science, University of Miami, 277-282, 1993.

Saha, S., Moorthi, S., Wu, X., Wang, J., Nadiga, S., Tripp, P., Behringer, D., Hou, Y., Chuang, H., Iredell, M., Ek, M., Meng, J., Yang, R., Mendez, M. P., van den Dool, H., Zhang, Q., Wang, W., Chen, M., and Becker, E.: NCEP Climate Forecast System Version 2 (CFSv2) Selected Hourly Time-Series Products. Research Data Archive at the National Center for Atmospheric Research, Computational and Information Systems Laboratory, updated monthly, https://doi.org/10.5065/D6N877VB, last access: 17 November 2016, 2011.

Snyder, R. L., Dobson, F. W., Elliott, J. A., and Long, R. B.: Array measurements of atmospheric pressure fluctuations above surface gravity waves, J. Fluid Mech., 102, 1-59, https://doi.org/10.1017/S0022112081002528, 1981.

Sørensen, O. R., Kofoed-Hansen, H., Rugbjerg, M., and Sørensen, L. S.: A third-generation spectral wave model using an unstructured finite volume technique, Proceedings of the 29th Intern. Conf. on Coastal Eng., 1, 894-906, https://doi.org/10.1142/9789812701916-0071, 2005.

SWAN: Swan Scientific and Technical Documentation, SWAN Cycle III, Version 41.01, 1-132, 2014.

Tolman, H. L. and Chalikov, D.: Source Terms in a ThirdGeneration Wind Wave Model, 26, https://doi.org/10.1175/15200485(1996)026<2497:STIATG>2.0.CO;2, 1996.

van der Westhuysen, A. J., Zijlema, M., and Battjes, J. A.: Nonlinear saturation-based whitecapping dissipation in SWAN for deep and shallow water, Coast. Eng., 54, 151-170, https://doi.org/10.1016/j.coastaleng.2006.08.006, 2007.

Young, I. R. and Babanin, A. V.: Spectral Distribution of Energy Dissipation of Wind-Generated Waves due to Dominant Wave Breaking, J. Phys. Oceanogr., 36, 376-394, https://doi.org/10.1175/JPO2859.1, 2006a.

Young, I. R. and Babanin, A. V.: The form of the asymptotic depth-limited wind wave frequency spectrum, J. Geophys. Res.-Oceans, 111, 1-15, https://doi.org/10.1029/2005JC003398, 2006b.

Young, I. R., Banner, M. L., Donelan, M. A., Babanin, A. V., Melville, W. K., Veron, F., and McCormick, C.: An integrated system for the study of wind-wave source terms in finite-depth water, J. Atmos. Ocean. Tech., 22, 814-831, https://doi.org/10.1175/JTECH1726.1, 2005.

Yuan, Y., Tung, C. C., and Huang, N. E.: Statistical Characteristics of Breaking Waves, in: Wave Dynamics and Radio Probing of the Ocean Surface, Springer US, Boston, MA, 265-272, https://doi.org/10.1007/978-1-4684-8980-4-18, 1986.

Zieger, S., Babanin, A. V., Erick Rogers, W., and Young, I. R.: Observation-based source terms in the third-generation wave model WAVEWATCH, Ocean Model., 96, 2-25, https://doi.org/10.1016/j.ocemod.2015.07.014, 2015.

Zijlema, M., Van Vledder, G. P., and Holthuijsen, L. H.: Bottom friction and wind drag for wave models, Coast. Eng., 65, 19-26, https://doi.org/10.1016/j.coastaleng.2012.03.002, 2012. 